\title{
Synthesis, photophysical and electrochemical investigation of dinuclear tetrazolato-bridged rhenium complexes
}

\section{Phillip J. Wright, ${ }^{\dagger}$ Sara Muzzioli, ${ }^{\ddagger}$ Melissa V. Werrett,${ }^{\dagger}$ Paolo Raiteri, ${ }^{\dagger}$ Brian W. Skelton, ${ }^{\S}$ Debbie S. Silvester, ${ }^{\dagger}$ Stefano Stagni, ${ }^{*} *$ Massimiliano Massi ${ }^{*}{ }^{\dagger}$}

${ }^{\dagger}$ Department of Chemistry, Curtin University, Kent Street, Bentley WA 6102, Australia.

$\$$ Department of Physical and Inorganic Chemistry, University of Bologna, viale del Risorgimento, I-40126 Bologna, Italy.

${ }^{\S}$ Center for Microscopy, Characterization and Analysis, University of Western Australia, Crawley 6009 WA, Australia.

Corresponding author email: m.massi@curtin.edu.au, stefano.stagni@unibo.it

\begin{abstract}
Starting from anionic tetrazole-based ligands, namely 5-(4'-cyanophenyl)tetrazolate and 5-(4'pyridyl)tetrazolate, mononuclear and dinuclear complexes of $f a c-\left[\operatorname{Re}(\mathrm{CO})_{3}(\mathbf{p h e n})\right]^{+}(\mathbf{p h e n}=1,10$-phenanthroline $)$ were prepared and characterized. For the mononuclear complexes, regioselective coordination of the metal fragments on the negatively charged tetrazolato ring is exclusively obtained. Coordination to the benzonitrile and pyridine groups was achieved by previous alkylation of the tetrazole ring. Dinuclear complexes were obtained by treatment of the corresponding mononuclear tetrazole-bound complexes with $f a c-\left[\operatorname{Re}(\mathrm{CO})_{3}(\mathbf{p h e n})(\mathrm{THF})\right]^{+}$. The second rhenium fragment coordinated either to the pyridine ring or, in the case of the benzonitrile ligand, to the tetrazole ring. The electrochemical properties were probed in an imidazolium ionic liquid, highlighting reduction processes centered on the phen ligand and oxidation processes localized on the metal. The photophysical properties of the complexes are characterized by phosphorescent emission from triplet metal-to-ligand charge transfer excited states, with trends in the lifetime and quantum yield in qualitative agreement with the energy gap law. The two dinuclear complexes show almost superimposable emission profiles: in the 5-(4'cyanophenyl)tetrazolate-bridged complex, the two metal fragments coordinated to the tetrazole are equivalent and share a positive charge of +1 . On the other hand, the photophysical properties of the 5-(4'pyridyl)tetrazolatebridged dinuclear complex suggest energy transfer between the two metal centers.
\end{abstract}




\section{Introduction}

The photophysical properties of Re complexes have attracted considerable interest stemming from their potential application in a variety of fields, including optical displays, sensors, catalysis, molecular electronics, and biological labelling. ${ }^{1-9}$ The most investigated $\operatorname{Re}$ complexes are the $\operatorname{Re}(\mathrm{I})$ tricarbonyl type with the general formulation $f a c-\left[\operatorname{Re}(\mathrm{CO})_{3}(\operatorname{diim})(\mathbf{L})\right]^{0 /+}$, where diim is a diimine ligand [e.g 1,10-phenathroline (phen)] and $\mathbf{L}$ a neutral or anionic monodentate ancillary ligand [e.g. pyridine (py)]. ${ }^{1}$ The emission of these complexes is ascribed to the phosphorescent decay from the lowest-energy triplet excited state, which has generally a metal-to-ligand charge transfer character $\left({ }^{3}\right.$ MLCT). ${ }^{10-12}$ Modulation of the HOMO-LUMO gap is achieved through chemical changes in either the diim ligand, thus directly affecting the LUMO orbital, and/or the ancillary ligand $\mathbf{L}$, with a consequent indirect shift of the HOMO orbital. ${ }^{1,13,14}$ Studies on a large library of Re(I) complexes have shown that the photophysical properties follow the trend dictated by the energy gap law, ${ }^{15}$ hence cationic fac$\left[\operatorname{Re}(\mathrm{CO})_{3}(\mathbf{d i i m})(\mathbf{L})\right]^{+}$complexes exhibit blue-shifted emissions, longer excited state lifetimes $(\tau)$ and increased quantum yields $(\Phi)$ with respect to their neutral analogues. ${ }^{1}$

While a vast number of luminescent $\operatorname{Re}(\mathrm{I})$ complexes have been reported to date, the investigation of monometallic dinuclear or multinuclear $\operatorname{Re}(\mathrm{I})$ complexes seems in comparison more limited. ${ }^{1,7,16-23}$ Asides from some dinuclear Re complexes bound to, for example, substituted pyridazine or 4,4'-bipyridine ligands, ${ }^{24-27}$ the photophysical properties of multinuclear assemblies of bridged $f a c-\left[\operatorname{Re}(\mathrm{CO})_{3}(\mathbf{d i i m})\right]^{+}$are sometimes inferior to the corresponding mononuclear complexes. This trend has been assigned to enhanced non-radiative pathways favored by vibrational deactivation due to an increased molecular complexity. ${ }^{1}$ Studies of multinuclear complexes where the Re centers are non-equivalent are even rarer. In some examples, Meyer and co-workers synthesized a series of dinuclear Re complexes bridged by a variety of 4,4'-bipyridine ligands. ${ }^{25,28}$ In those cases, the non-equivalent nature of the two Re complexes was achieved by the use of differently substituted 2,2'-bipyridyne ligands bound to the $\operatorname{Re}$ centers. The addition of electron-donating or electron-withdrawing substituents resulted in the destabilization or stabilization of the LUMO level, hence increasing or decreasing the relative energy of the MLCT transition, respectively. By combining cyclic voltammetry, electronic spectroscopy and transient detection, it was demonstrated that in such dinuclear complexes the two metal centers undergo electronic coupling via energy transfer. The energy transfer was found to be mediated by electron transfer, the latter being favored by the presence of a bridging ligand with an accessible $\pi^{*}$ delocalized system. ${ }^{28}$

To the best of our knowledge, no example has been reported of dinuclear rhenium complexes, bridged by $\pi$ conjugated ligands, where the non-equivalence of the two emissive rhenium centers originates from the direct 
modulation of the HOMO levels. Following our recent work on mononuclear Re(I) tetrazolato complexes, ${ }^{29,30}$ we have extended the investigation to dinuclear $\operatorname{Re}(\mathrm{I})$ complexes bridged by the tetrazolato ligands 5-(4'cyanophenyl)tetrazolate (1) and 5-(4'-pyridyl)tetrazolate (2). Our focus is to achieve bridged dinuclear $\operatorname{Re}(\mathrm{I})$ complexes where the two metal centers are electronically non-equivalent, e.g. one neutral complex bound to the anionic tetrazolato ring and the other cationic complex bound to either the nitrile or pyridine group. While the dinuclear complex bridged by 5-(4'-pyridyl)tetrazolate could be obtained, in the case of 5-(4'cyanophenyl)tetrazolate the desired complex was not formed and instead an unprecedented doubly coordinated tetrazole was obtained. To gain insight into the photophysical and electrochemical properties of the dinuclear complexes, we have also attempted to synthesise the corresponding four mononuclear model complexes, where the rhenium fragments are coordinated to the tetrazole ring in both 5-(4'-cyanophenyl)tetrazolate and 5-(4'pyridyl)tetrazolate, thus forming neutral mononuclear complexes, or to the nitrile and pyridine substituents, thus forming cationic mononuclear complexes.

\section{Results and Discussion}

Synthesis of the tetrazole ligands and the Re complexes. The synthesis of the tetrazole-based ligands $1 \mathrm{H}$ and $2 \mathrm{H}$ was achieved by 1,3-dipolar cycloaddition of $\mathrm{NaN}_{3}$ to the corresponding nitrile-containing substrates according to a previously reported methodology. ${ }^{31}$ To prepare the neutral rhenium complexes [Re1] and [Re2] (Figure 1), the halogenated precursor $f a c-\left[\operatorname{Re}(\mathrm{CO})_{3}(\text { phen }) \mathrm{Cl}\right]^{11}$ was directly treated with the corresponding tetrazole ligand and triethylamine in refluxing acetonitrile. Compared to the previously published procedure using solvato or triflato rhenium precursors, ${ }^{30,32}$ this one-step protocol avoids the use of light sensitive silver salts to remove the chloro ligand from the rhenium center and, more importantly, the starting $f a c-\left[\operatorname{Re}(\mathrm{CO})_{3}(\mathbf{p h e n}) \mathrm{Cl}\right]$ complex can be readily recovered in the purification step and recycled for further syntheses.

The synthesis of the cationic mononuclear rhenium complexes required the preparation of the N2-alkylated version of the $1 \mathrm{H}$ and $2 \mathrm{H}$ ligands (Figure 2). The alkylation was successfully achieved by treating $2 \mathrm{H}$ with $\mathrm{H}_{2} \mathrm{SO}_{4}$ and $\mathrm{CF}_{3} \mathrm{COOH}$ in tert-butanol, ${ }^{33}$ thus introducing a bulky tert-butyl substituent on the $\mathrm{N} 2$ atom of the tetrazole ring. On the other hand, when $\mathbf{1 H}$ was reacted under the same conditions, an acid catalysed hydrolysis of the nitrile group took place to yield the corresponding secondary N-tert-butyl amide. We therefore decided to alkylate the tetrazole ring in $\mathbf{1 H}$ with a benzyl group. The preparation of the corresponding cationic complexes was attempted in a two-step procedure, involving the generation of the solvato-complex $f a c$ - $\left[\operatorname{Re}(\mathrm{CO})_{3}(\mathbf{p h e n})(\mathrm{THF})\right]\left[\mathrm{OSO}_{2} \mathrm{CF}_{3}\right]$ followed by exchange of the labile THF molecule with the ligand $\mathbf{3}$ or $\mathbf{4}$ (Figure 2). In the case of the ligand $\mathbf{3}$, the 
spectroscopic data suggests that the nitrile group coordinates to the rhenium center, as witnessed by the shift to higher wavenumbers that is displayed by the $\mathrm{CN}$ group upon coordination, from 2230 to $2263 \mathrm{~cm}^{-1} \cdot{ }^{34}$ However, the coordination of the nitrile group was found to be rather labile and its dissociation was monitored by ${ }^{1} \mathrm{H}-\mathrm{NMR}$ (see Supporting Information, Figure S1). The preparation of the pyridine-coordinated complex [Re4] $\mathrm{PF}_{6}$ was obtained following the same procedure and the complex was isolated as the corresponding $\mathrm{PF}_{6}{ }^{-}$salt. The successful salt metathesis could be monitored by the appearance of a broad band at $828 \mathrm{~cm}^{-1}$ in the IR spectrum of [Re4] $\mathrm{PF}_{6}{ }^{35}$

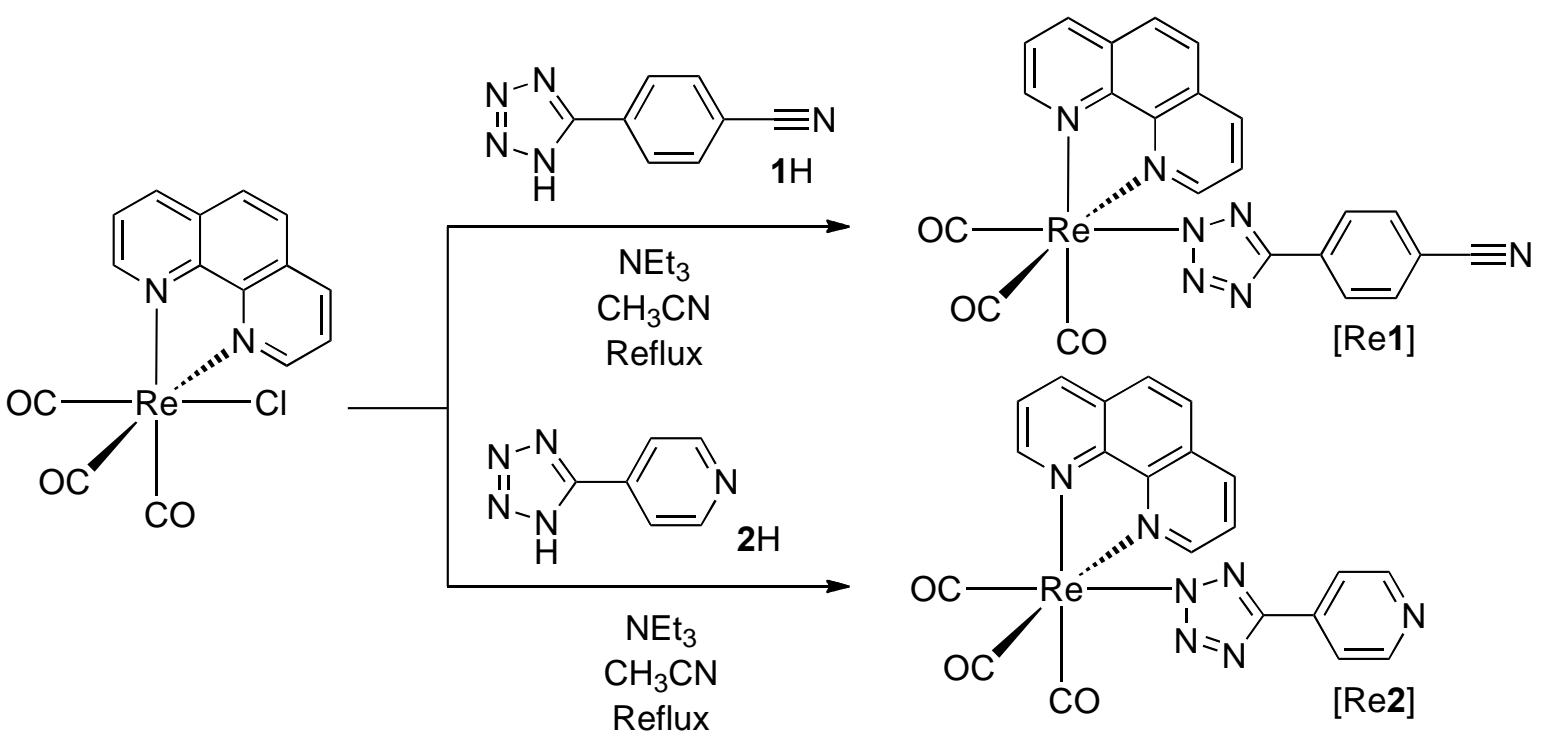

Figure 1. Synthetic pathways for the preparation of the neutral complexes [Re1] and [Re2]. 

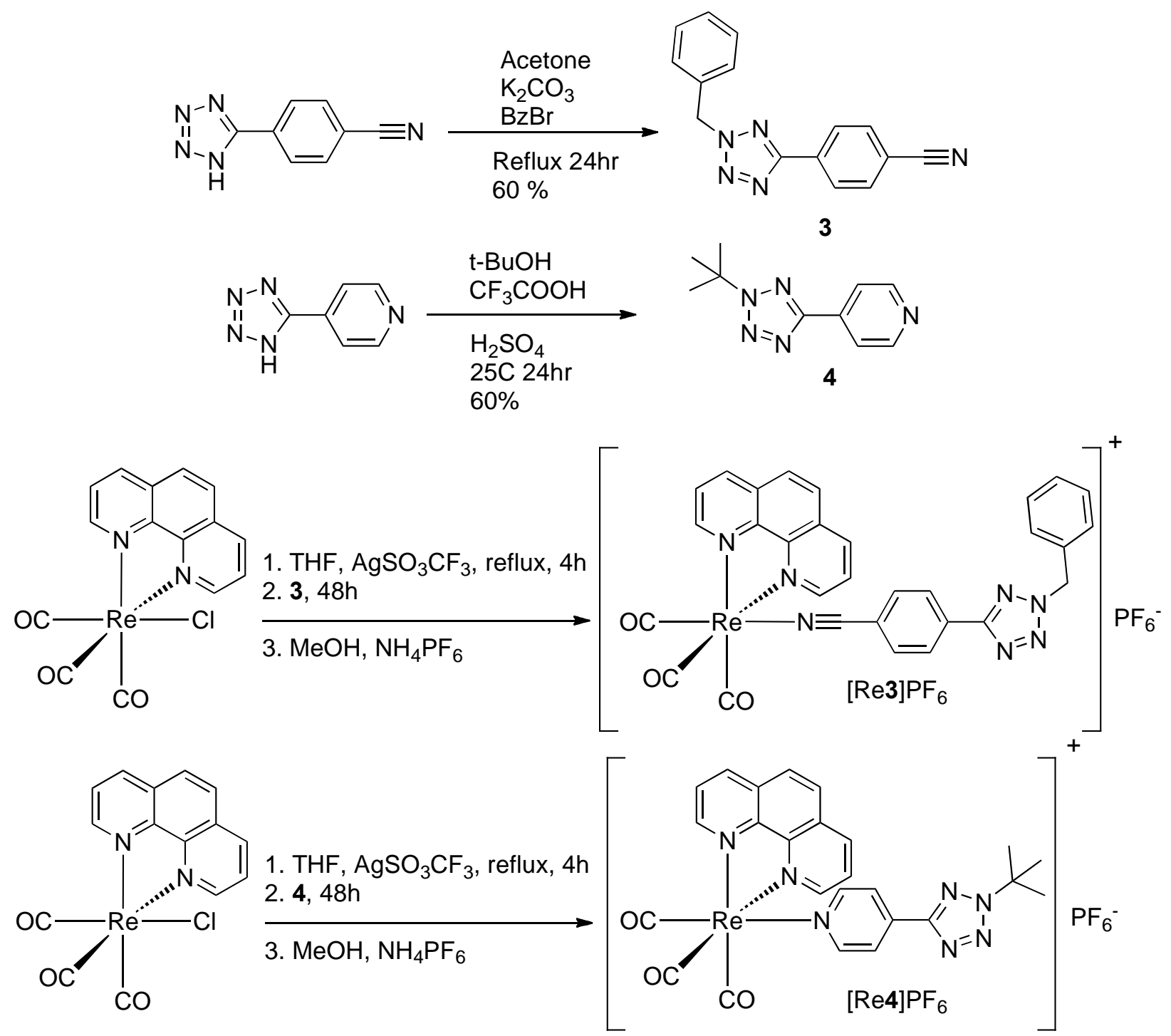

Figure 2. Synthetic pathways for the preparation of the ligands $\mathbf{3}$ and $\mathbf{4}$, and the neutral complexes $\left[\operatorname{Re}^{3}\right] \mathrm{PF}_{6}$ and $[\mathrm{Re} 4] \mathrm{PF}_{6}$.

The preparation of the dinuclear cationic complexes was attempted by treating the solvato-complex fac$\left[\operatorname{Re}(\mathrm{CO})_{3}(\mathbf{p h e n})(\mathrm{THF})\right]^{+}$with either $[\operatorname{Re} 1]$ or $[\operatorname{Re} 2]$ in refluxing THF (Figure 3 ). In the case of fac$\left[\operatorname{Re}(\mathrm{CO})_{3}(\mathbf{p h e n})(\mathrm{THF})\right]^{+}$and $[\operatorname{Re} \mathbf{1}]$, the targeted dinuclear species bearing the rhenium centers coordinated to the tetrazole and to the nitrile group was not obtained, since the IR spectrum displayed the presence of a nitrile band at $2233 \mathrm{~cm}^{-1} \cdot{ }^{34}$ Nevertheless, the spectroscopic data suggested the presence of two rhenium centers, as the ${ }^{1} \mathrm{H}-\mathrm{NMR}$ spectrum shows two phen systems versus one tetrazole ligand. The spectroscopic evidence of the dimeric species could be rationalized by the analysis of the X-ray crystal structure (see below), where the unexpected formation of a doubly coordinated tetrazole in $\left[\operatorname{Re}_{2} 1\right] \mathrm{PF}_{6}$ was observed, as schematized in Figure 3. The synthesis of 
[Re2Re] $\mathrm{PF}_{6}$ was achieved using the same methodology. The structural feature was indeed demonstrated by the Xray crystal structure in the solid state (see below). However, ${ }^{1} \mathrm{H}-\mathrm{NMR}$ data also proved that the same structure is retained in solution. The difference between the coordination modes in $\left[\operatorname{Re}_{2} 1\right] \mathrm{PF}_{6}$ and $[\operatorname{Re} 2 \mathrm{Re}] \mathrm{PF}_{6}$ might be ascribed to i) a significantly lower nucleophilicity of the nitrile group with respect to the pyridine and ii) a much weaker $\pi$ accepting nature of the nitrile. These characteristics make the nitrile a weak ligand for a $\operatorname{Re}(\mathrm{I})$ center and therefore, despite the high steric hindrance, the second metal center coordinates to the tetrazole ring in $\left[\operatorname{Re}_{2} \mathbf{1}\right] \mathrm{PF}_{6}$. This behaviour seems to be unique for rhenium, as analogous monometallic dinuclear complexes of iron and ruthenium bridged by the same ligand $\mathbf{1}$ did not show double coordination at the tetrazole ring. ${ }^{36,37}$ Interestingly though, when comparing the structure of $\left[\operatorname{Re}_{2} \mathbf{1}\right] \mathrm{PF}_{6}$ with the product obtained by treating fac$\left[\operatorname{Re}(\mathrm{CO})_{3}(\mathbf{p h e n})(\mathrm{THF})\right]^{+}$with $\mathbf{3}$, in the former case a double coordination of the tetrazole ring occurred, whereas in the latter the rhenium coordinates to the nitrile group. The higher nucleophilicity of the coordinated tetrazole in [Re1] might be ascribed to the presence of $\pi$-backbonding from the Re to the tetrazole, which is absent in the case of a tetrazole ring alkylated by a tert-butyl group. This argument is formulated on the assumption that the steric bulkyness of the $f a c-\left[\operatorname{Re}(\mathrm{CO})_{3}(\mathbf{p h e n})\right]^{+}$fragment is not significantly lower than the bulkiness of a tert-butyl substituent, henceforth the difference in the coordination modes does not have a kinetic origin.

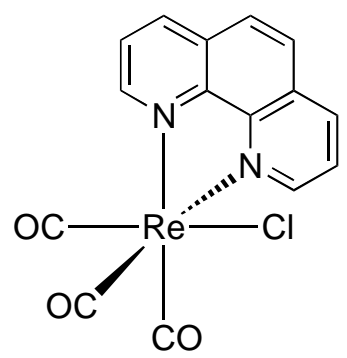

1. $\mathrm{THF}, \mathrm{AgSO}_{3} \mathrm{CF}_{3}$, reflux, $4 \mathrm{~h}$ 2. [Re1], $24 \mathrm{~h}$

3. $\mathrm{MeOH}, \mathrm{NH}_{4} \mathrm{PF}_{6}$
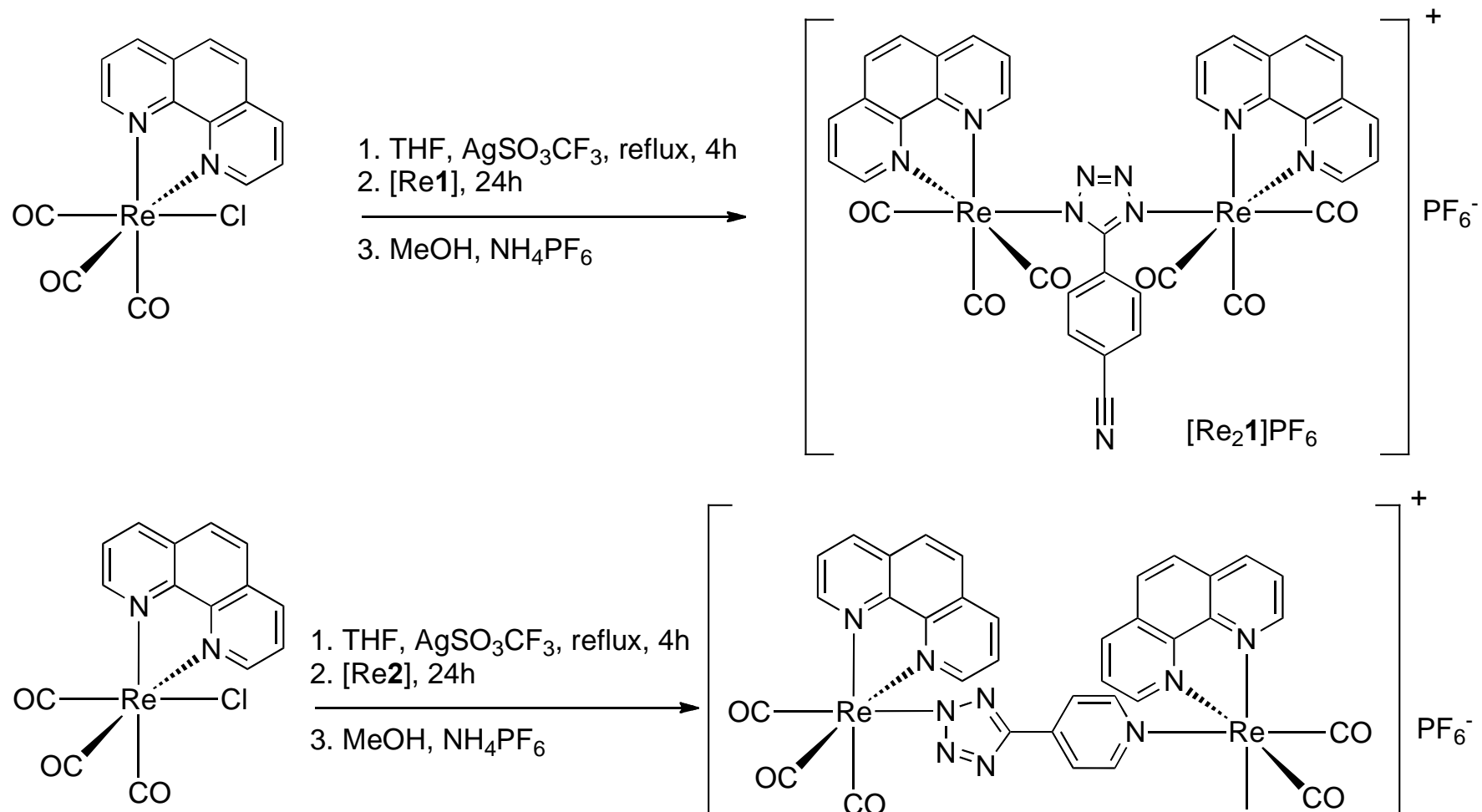

1. $\mathrm{THF}, \mathrm{AgSO}_{3} \mathrm{CF}_{3}$, reflux, $4 \mathrm{~h}$ 2. [Re2], 24h

3. $\mathrm{MeOH}, \mathrm{NH}_{4} \mathrm{PF}_{6}$
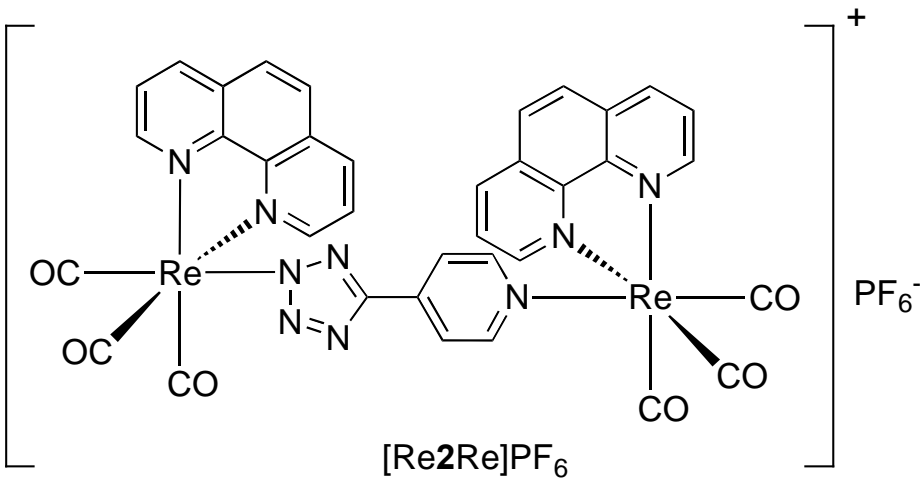

Figure 3. Synthetic pathways for the preparation of the dinuclear complexes $\left[\operatorname{Re}_{2} 1\right] \mathrm{PF}_{6}$ and $[\mathrm{Re} 2 \mathrm{Re}] \mathrm{PF}_{6}$. 
Spectroscopic characterization. All the complexes show characteristic carbonyl stretching bands as expected from the local $C_{S}$ point group, e.g. the totally symmetric in-phase stretching $\mathrm{A}^{\prime}(1)$, the totally symmetric out-of-phase stretching $A^{\prime}(2)$, and the asymmetric stretching $A^{\prime \prime} .38-41$ The values of the recorded frequencies are summarized in Table 1. The relative frequencies of the bands, especially in the case of the $A^{\prime}(1)$, also reflect the nature of the compounds in terms of electron density on the rhenium center. In the case of $\left[\operatorname{Re}_{2} \mathbf{1}\right] \mathrm{PF}_{6}$ and [Re2Re]PF 6 only one set of bands is visible in the IR spectra, whose frequency values lie between the ones found for the mononuclear complexes [Re1] and [Re2] and the cationic [Re4] $\mathrm{PF}_{6}$ complex. While it is expected that the dinuclear complex $\left[\operatorname{Re}_{2} 1\right] \mathrm{PF}_{6}$ exhibits only one set of carbonyl bands, it is surprising that the same happens for [Re2Re] $\mathrm{PF}_{6}$ due to the formally non-equivalent nature of the two metal centers. The result suggests that in $[\operatorname{Re} 2 \mathrm{Re}] \mathrm{PF}_{6}$ the ligand favors the electronic conjugation between the two metal centers with consequent coalescence of the carbonyl bands. A similar behaviour is observed for the photophysical properties of $[\mathrm{Re} 2 \mathrm{Re}] \mathrm{PF}_{6}$ (see below).

Table 1. Carbonyl ligand stretching frequencies $\left(\mathrm{cm}^{-1}\right)$ for the synthesized rhenium complexes in the solid state.

\begin{tabular}{lccc}
\multicolumn{1}{c}{ Complex } & $\mathbf{A}^{\prime}(\mathbf{1})$ & $\mathbf{A}^{\prime}(\mathbf{2})$ & $\mathbf{A}^{\prime \prime}$ \\
\hline$[\operatorname{Re} 1]$ & 2017 & 19121896 \\
{$[\operatorname{Re} 2]$} & 2020 & $1898^{[\mathrm{a}]}$ \\
{$[\operatorname{Re} 4] \mathrm{PF}_{6}$} & 2030 & $1906^{[\mathrm{a}]}$ \\
{$\left[\operatorname{Re}_{2} \mathbf{1}\right] \mathrm{PF}_{6}$} & 2027 & $1906^{[\mathrm{a}]}$ \\
{$[\operatorname{Re} 2 \operatorname{Re}] \mathrm{PF}_{6}$} & 2025 & $1895^{[\mathrm{a}]}$
\end{tabular}

[a] The $\mathrm{A}^{\prime}(2)$ and $\mathrm{A}^{\prime \prime}$ modes are superimposed into a single broad band.

A summary of the NMR data including $\mathrm{H}_{\text {ortho }}, \mathrm{H}_{\text {meta }}$, and C5 (see Experimental Section for the assignment of the peaks) is reported in Table 2. The NMR spectra readily confirm the proposed structures of the mononuclear complexes $[\operatorname{Re} 1]$ and $[\operatorname{Re} 2]$ in agreement with the X-ray diffraction data (see below). In the ${ }^{13} \mathrm{C}-\mathrm{NMR}$, the $\delta$ value of the tetrazolic $\mathrm{C} 5$ atom between 161 and $160 \mathrm{ppm}$ indicates co-planarity between the two rings in the ligand and hence confirms the regioselective complexation of the tetrazole ring at the N2 position. ${ }^{42-46}$ The same argument can be used in the case of [Re4] $\mathrm{PF}_{6}$ to demonstrate the coordination of the rhenium fragment to the pyridine $\mathrm{N}$ atom. The NMR data for the dinuclear $\left[\operatorname{Re}_{2} 1\right] \mathrm{PF}_{6}$ evidenced that the species exists in solution as an equilibrium of "tautomers", where the rhenium fragment coordinates to the N1 and N2 atoms of the tetrazole ring as schematized in Figure 4. On the other hand, no equilibrium was present in the NMR data of $\left[\operatorname{Re} 2 \mathrm{Re}_{\mathrm{PF}} \mathrm{P}_{6}\right.$, in support to the 
coordination of one rhenium center to the N2 atom of the tetrazole ring with the second rhenium fragment bound to the pyridine $\mathrm{N}$ atom. See Supporting Information and Figure S2 for the detailed NMR studies of the two dinuclear complexes.

Table 2. Selected NMR data including $\mathrm{H}_{\text {ortho }}, \mathrm{H}_{\text {meta }}$, and $\mathrm{C} 5$ for the synthesized complexes.

\begin{tabular}{lcccc}
\multicolumn{1}{c}{ Complex } & $\mathbf{H}_{\text {ortho }}$ & $\mathbf{H}_{\text {meta }}$ & C5 & solvent \\
\hline$[\operatorname{Re} 1]$ & 7.67 & 7.75 & 161.1 & $\mathrm{~d}_{6}$-DMSO \\
{$[\operatorname{Re} 2]$} & 7.42 & 8.48 & 160.6 & $\mathrm{~d}_{6}$-DMSO \\
{$[\operatorname{Re} 4] \mathrm{PF}_{6}$} & 7.79 & 8.45 & 161.5 & $\mathrm{CD}_{3} \mathrm{CN}$ \\
{$\left[\operatorname{Re}_{2} 1\right] \mathrm{PF}_{6}$} & 7.19 & 7.62 & $-{ }^{[a]}$ & $\mathrm{CDCl}_{3}$ \\
{$[\operatorname{Re} 2 \mathrm{Re}] \mathrm{PF}_{6}$} & 7.27 & 8.08 & 160.5 & $\mathrm{CD}_{3} \mathrm{CN}$
\end{tabular}

[a] The signal could not be observed due to very weak intensity.

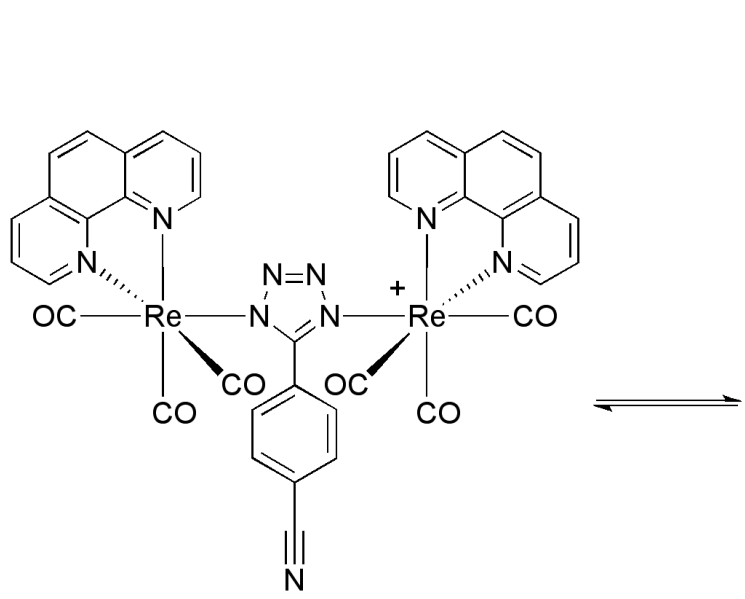

$\mathrm{N} 1, \mathrm{~N} 4$

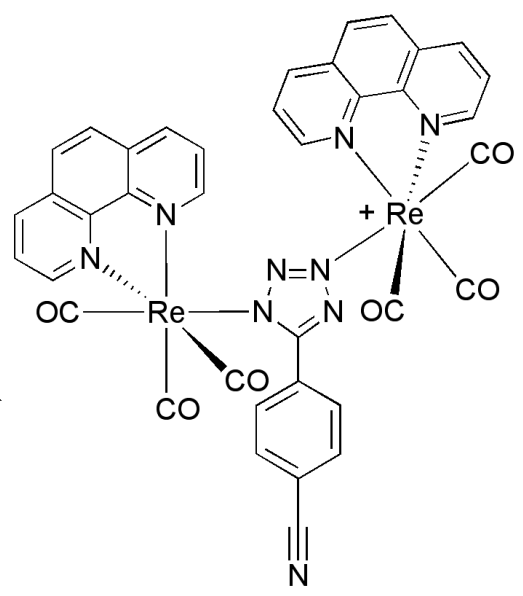

isomer

$\mathrm{N} 1, \mathrm{~N} 3$

isomer

Figure 4. Equilibrium between the N1,N4 and N1,N3 linkage isomers of the dinuclear complex $\left[\operatorname{Re}_{2} 1\right] \mathrm{PF}_{6}$.

Structural characterization. The structures of the prepared complexes are reported in Figure 5 (see Supplementary Information for Selected Bond Lengths and Angles). [Re1] crystallizes in the orthorhombic space group $P b c a$, while [Re2] crystallizes in the monoclinic space group $C 2 / c$. In both complexes the rhenium centers are hexacoordinated with slightly distorted octahedral geometries. The carbonyl ligands are orientated in facial configuration, in agreement with the spectroscopic data. The structures also confirm the coordination of the Re center to the $\mathrm{N} 2$ atom of the tetrazolato ligands $\mathbf{1}^{-}$and $\mathbf{2}^{-}$. The crystal packing of [Re2] is such that the phen ligands 
are involved in $\pi$-stacking between neighbouring complexes related by an inversion center, with a plane-to-plane distance of 3.473(4) ̊.

The cationic complex $[\operatorname{Re} 4] \mathrm{PF}_{6}$ crystallizes in the monoclinic space group $P 2_{1} / n$. The coordination environment of the rhenium center is analogous with the previous Re tetrazolato complexes. The bond length between the Re and the pyridine $\mathrm{N}$ atom is 2.207(3) $\AA$ and slightly elongated with respect to the Re-N(tetrazole) bonds in complexes [Re1] and [Re2], 2.174(2) and 2.176(2) ̊ respectively. The tetrazole and phenyl rings lie planar with respect to each other, thus favoring interannular conjugation.

The complex $\left[\operatorname{Re}_{2} 1\right] \mathrm{PF}_{6}$ crystallizes in the triclinic space group $P \overline{1}$. The two rhenium centers are bridged via the tetrazole ring, binding to the $\mathrm{N} 1$ and $\mathrm{N} 4$ atoms respectively in a $\mu_{2}-\eta^{1}(\mathrm{~N} 1): \eta^{1}(\mathrm{~N} 4)$ fashion. This linkage isomer seems to be the only one present in the lattice, and no evidence of the $\mu_{2}-\eta^{1}(\mathrm{~N} 1): \eta^{1}(\mathrm{~N} 3)$ binding mode is found. The complex possesses pseudo mirror symmetry about the bridging ligand. The dihedral angles between the plane of the benzonitrile group and the planes of the two phen groups are $9.4(2)^{\circ}$ and $3.1(2)^{\circ}$ with the dihedral angle between the planes of the two phen ligands being $8.2(1)^{\circ}$. The dihedral angle between the benzonitrile group and the tetrazole ring is $81.4(2)^{\circ}$. The two rings are forced to twist from a coplanar arrangement as an effect of the steric hindrance caused by the coordination of the two Re centers to the N1 and N4 atoms of the tetrazole ring. The Re-N bonds to the tetrazole ring are not co-linear, the structure being bent at the tetrazole group. The angles between these bonds and those normal to the plane of the tetrazole ring are $79.5(1)$ and $95.7(1)^{\circ}$ respectively. 

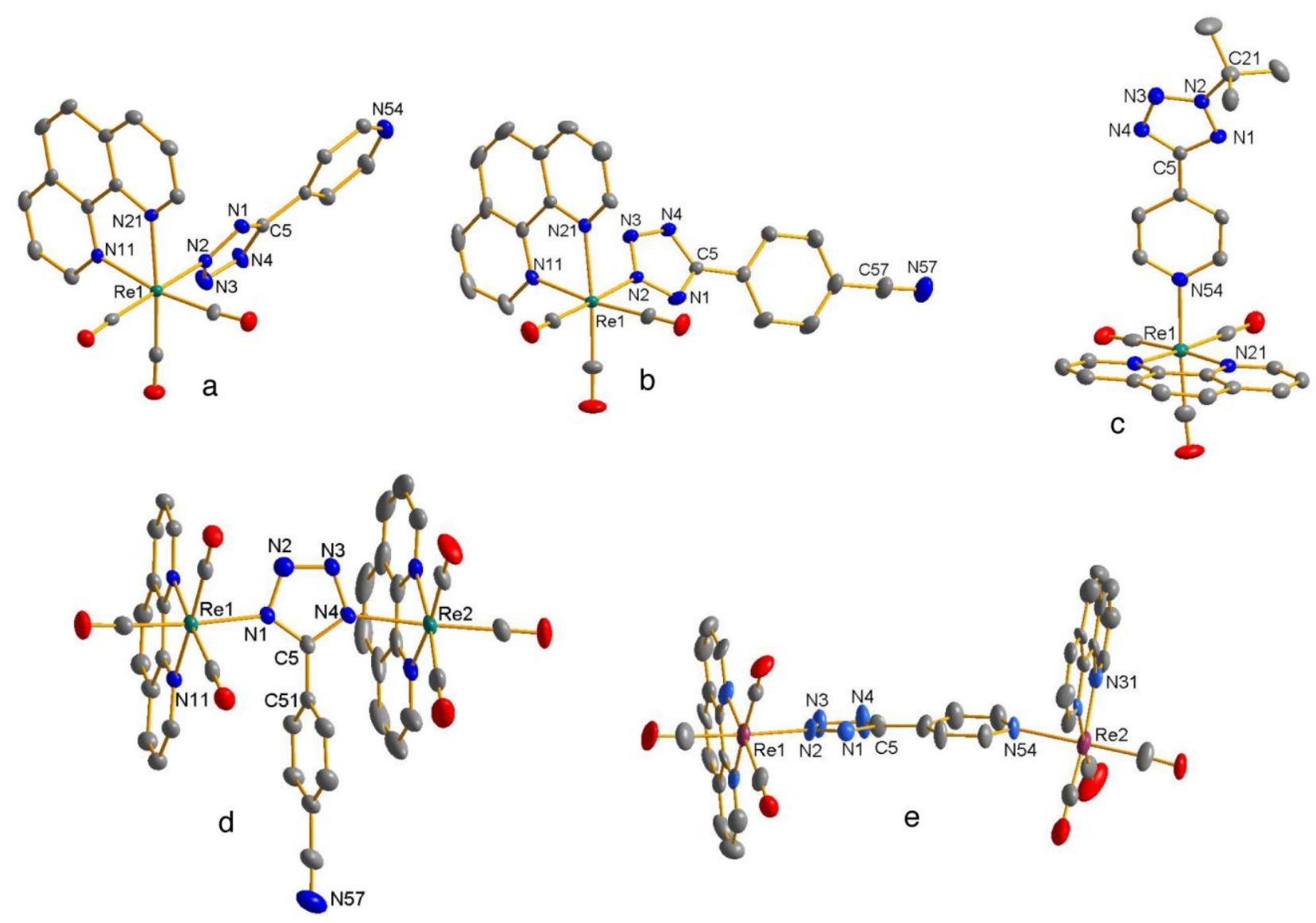

Figure 5. X-ray crystal structures of the synthesized complexes with thermal ellipsoids drawn at 50\% probability: a) $[\operatorname{Re} 1]$, b) $[\operatorname{Re} 2]$, c) $[\operatorname{Re} 4] \mathrm{PF}_{6}$, d) $\left[\operatorname{Re}_{2} 1\right] \mathrm{PF}_{6}$, e) $[\mathrm{Re} 2 \mathrm{Re}] \mathrm{PF}_{6}$. Solvent molecules and counteranions, when present, have been omitted for clarity.

The complex $[\mathrm{Re} 2 \mathrm{Re}] \mathrm{PF}_{6}$ crystallizes in the triclinic space group $P \overline{1}$. The two rhenium centers are analogous to all the previously described complexes. The structure confirms the $\mu_{2}-\eta^{1}(\mathrm{~N} 2): \eta^{1}(\mathrm{Npy})$ binding mode of the ligand 2. The py and tetrazole rings are almost coplanar with the dihedral angle between the two planes being $7.3(5)^{\circ}$. Although the Re1 atom is virtually coplanar with the tetrazole ring ( $\delta \operatorname{Re} 10.03(2) \AA$ ), $\operatorname{Re} 2$ is considerably out of plane of the py ring ( $\delta \operatorname{Re} 20.43(3) \AA)$. The two phen ligands are not coplanar, the dihedral angle between the two being $25.2(3)^{\circ}$. 
Table 3. Half wave potentials $\left(E_{1 / 2}\right)$ for the prepared mono and dinuclear rhenium complexes.

\begin{tabular}{|c|c|c|c|}
\hline Complex & $\begin{array}{c}E_{1 / 2}(01 / 01 ') \\
{[\mathrm{V}] \text { vs. }\left(\mathrm{Fc} / \mathrm{Fc}^{+}\right)}\end{array}$ & $\begin{array}{c}E_{1 / 2}\left(\mathrm{O} 2 / \mathrm{O2}^{\prime}\right) \\
{[\mathrm{V}] \text { vs. }\left(\mathrm{Fc} / \mathrm{Fc}^{+}\right)}\end{array}$ & $\begin{array}{c}E_{1 / 2}\left(\mathrm{R} 1 / \mathrm{R}^{\prime}\right) \\
{[\mathrm{V}] \mathrm{vs} .\left(\mathrm{Fc} / \mathrm{Fc}^{+}\right)}\end{array}$ \\
\hline$f a c-\left[\operatorname{Re}(\mathrm{CO})_{3}(\right.$ phen $\left.) \mathrm{Cl}\right]$ & 0.96 & 1.56 & -1.62 \\
\hline$f a c-\left[\operatorname{Re}(\mathrm{CO})_{3}(\mathbf{p h e n})(\mathbf{T z P h})\right]^{[\mathrm{a}]}$ & 1.12 & 1.45 & -1.61 \\
\hline$[\operatorname{Re} 1]$ & 1.14 & 1.52 & -1.62 \\
\hline$[\operatorname{Re} 2]$ & 1.22 & - & -1.60 \\
\hline$[\mathrm{Re} 4] \mathrm{PF}_{6}$ & 1.66 & - & -1.49 \\
\hline$\left[\operatorname{Re}_{2} 1\right] \mathrm{PF}_{6}$ & $0.95,1.13$ & $1.29,1.47$ & -1.60 \\
\hline$[\mathrm{Re} 2 \mathrm{Re}] \mathrm{PF}_{6}$ & $1.18,1.51$ & - & $-1.50^{[\mathrm{b}]},-1.66^{[\mathrm{b}]}$ \\
\hline
\end{tabular}

[a] The synthesis and photophysical properties of this complex are described elsewhere. ${ }^{30}[\mathrm{~b}]$ The value corresponds to the position of the peaks instead of the half-wave potential, as the back peaks cannot be precisely located.

Electrochemical properties. The electrochemical behaviour of the complexes was investigated using cyclic voltammetry $(\mathrm{CV})$, and a summary of the data is reported in Table 3. Two more complexes, fac$\left[\operatorname{Re}(\mathrm{CO})_{3}(\right.$ phen $\left.) \mathrm{Cl}\right]$ and the previously reported $f a c-\left[\operatorname{Re}(\mathrm{CO})_{3}(\mathbf{p h e n})(\mathbf{T z P h})\right]^{30}($ where $\mathbf{T z P h}=5-$ phenyltetrazolate), were investigated to analyze the electrochemical trend on changing the nature of the ancillary ligand in the rhenium complexes. We have already established the advantages of performing these types of measurement in room temperature ionic liquids (RTILs) instead of common organic solvents. ${ }^{29}$ In this work, the solvent chosen was the hydrophobic RTIL $\left[\mathrm{C}_{6} \mathrm{mim}\right][\mathrm{FAP}]$, namely 1-hexyl-3-methylimidazolium tris(pentafluoroethyl)trifluorophosphate. ${ }^{47}$

The voltammetric curves of all the mononuclear complexes are reported in the Supplementary Information (see Figures S3-5). In all the neutral mononuclear complexes the reduction peak (R1/R1') around -1.62 to $-1.60 \mathrm{~V}$ is assigned to phen-centered one-electron transfer. ${ }^{11}$ Two oxidation processes (O1/O1' and O2/O2'), are observed for $f a c-\left[\operatorname{Re}(\mathrm{CO})_{3}(\mathbf{p h e n}) \mathrm{Cl}\right], f a c-\left[\operatorname{Re}(\mathrm{CO})_{3}(\mathbf{p h e n})(\mathbf{T z P h})\right]$ and $[\operatorname{Re} \mathbf{1}]$, and they are assigned to oxidations occurring mainly on the rhenium center (e.g. $\operatorname{Re}(\mathrm{I}) \rightarrow \operatorname{Re}(\mathrm{II})+\mathrm{e}^{-}$and $\left.\operatorname{Re}(\mathrm{II}) \rightarrow \operatorname{Re}(\mathrm{III})+\mathrm{e}^{-}\right)$with the involvement of the tetrazolato ligand (aside from the chloro complex). ${ }^{47}$ The trend in the oxidation potential values of $01 / 01$ ' is in 
agreement with the relative electron density on the rhenium center, which is modulated by variation of the $\pi$ donating or $\pi$-accepting nature of the ancillary ligand. Only one oxidation process is observed for [Re2] within the available potential window. The same trend is also observed for the $\mathrm{O} 1 / \mathrm{O} 1$ ' process on $[\mathrm{Re}] \mathrm{PF}_{6}$ that occurs at $E_{1 / 2}$ $=1.66 \mathrm{~V}$, in agreement with the positive charge of the complex and hence the reduced electron density on the metal center. Both the reduction and oxidation processes appear to be diffusion controlled, since a plot of peak current against the square root of scan rate was linear over a range of 5 to $1000 \mathrm{mVs}^{-1}$ (plots not shown). The peak-to-peak separations of R1/R1' and O1/O1' are typically 80-100 mV, consistent with a kinetically fast electrochemical step. This separation is comparable to the separation of the $\mathrm{Fc} / \mathrm{Fc}^{+}$redox couple $(90 \mathrm{mV})$, which is known to have relatively fast kinetics in RTILs, but larger than the $60 \mathrm{mV}$ expected for fast, one-electron processes in traditional solvents, ${ }^{48}$ due to different contributions from double layer effects in ionic liquids. ${ }^{49,50}$ The second metal-centered oxidation $\mathrm{O} 2 / \mathrm{O}^{\prime}$ has quasi-reversible kinetics with a peak-to-peak separation of $\sim 160-250 \mathrm{mV}$. The redox couple $\mathrm{R} 1 / \mathrm{R} 1$ ' appears to be fully chemically reversible in $\left[\mathrm{C}_{6} \mathrm{mim}\right][\mathrm{FAP}]$, but O1/O1' shows some degree of chemical irreversibility due to the smaller sized reverse peak, suggesting some degree of follow-up chemistry, but this appears to be relatively slow on the voltammetric timescale.

Figure 6 shows the cyclic voltammograms for the dinuclear complexes $\left[\operatorname{Re}_{2} 1\right] \mathrm{PF}_{6}$ and $[\operatorname{Re} 2 \mathrm{Re}] \mathrm{PF}_{6}$. A twoelectron $R_{1} / R_{1}$ ' reduction process appears for $\left[\mathrm{Re}_{2} 1\right] \mathrm{PF}_{6}$ at $-1.60 \mathrm{~V}$ and is again assigned to the reduction of both phen ligands. The $\mathrm{R} 1 / \mathrm{R} 1$ ' process of $[\mathrm{Re} 1]$ and $\left[\mathrm{Re}_{2} 1\right] \mathrm{PF}_{6}$ appear to be unchanged in terms of electrochemical reversibility. The oxidative region of $\left[\operatorname{Re}_{2} 1\right] \mathrm{PF}_{6}$ appears more complicated with at least four distinct oxidative processes in the region $0.95-1.47 \mathrm{~V}$. We have tentatively assigned the four peaks at higher potentials to the first and second metal oxidations for both of the two separate metal centers. The other peaks present in the voltammogram of $\left[\operatorname{Re}_{2} 1\right] \mathrm{PF}_{6}$ (from -0.2 to $0.8 \mathrm{~V}$ ) may be a result of the fact that this compound exists as an equilibrium between two isomers, and there are oxidation steps associated with both isomers, potentially a result of their interaction and oxidation at the Au electrode surface. Remarkably, the first oxidation potential of $\left[\operatorname{Re}_{2} 1\right] \mathrm{PF}_{6}$ occurs at $0.95 \mathrm{~V}$ despite the positively-charged nature of the complex. We have ascribed the low potential to the fact that the tetrazole ring is unable to donate electronic charge to the benzonitrile ring as a result of the almost perpendicular arrangement of the two rings. The tetrazole ring has therefore an increased electron density that facilitates the oxidation of the complex.

In the case of $[\mathrm{Re} 2 \mathrm{Re}] \mathrm{PF}_{6}$, two closely lying one-electron reduction processes centered on the phen ligands appear at -1.50 and $-1.66 \mathrm{~V}$. Despite their overlapping nature, both of these peaks show some degree of chemical reversibility. The oxidation region shows two processes, both of which are ascribed to a one electron O1/O1' process occurring on each metal center. This conclusion was obtained by comparing the data with the 
voltammograms of $[\mathrm{Re} 2]$ and $[\mathrm{Re} 4] \mathrm{PF}_{6}$, both of which show only one oxidation occurring within the available potential window (see SI Figures 3 and 4). The peak-to-peak separations of the O1/O1' redox couple are 68 and $199 \mathrm{mV}$, respectively, suggesting fast kinetics for the first metal oxidation and intermediate kinetics for the second metal oxidation. Also noteworthy is that the oxidation of the $\operatorname{Re}(-\mathbf{p y})$ in $[\operatorname{Re} 2 \operatorname{Re}] \mathrm{PF}_{6}$ occurs at a lower potential with respect to the oxidation of $\operatorname{Re}(-\mathbf{p y})$ in $[\mathrm{Re} 4] \mathrm{PF}_{6}\left(\mathrm{E}_{1 / 2}=1.51\right.$ and $1.66 \mathrm{~V}$, respectively). This shift could be ascribed to the presence of a $\pi$-donating Re center bound to the tetrazole ring in $[\mathrm{Re} 2 \mathrm{Re}] \mathrm{PF}_{6}$ instead of an alkyl substituent in $[\operatorname{Re} 4] \mathrm{PF}_{6}$.
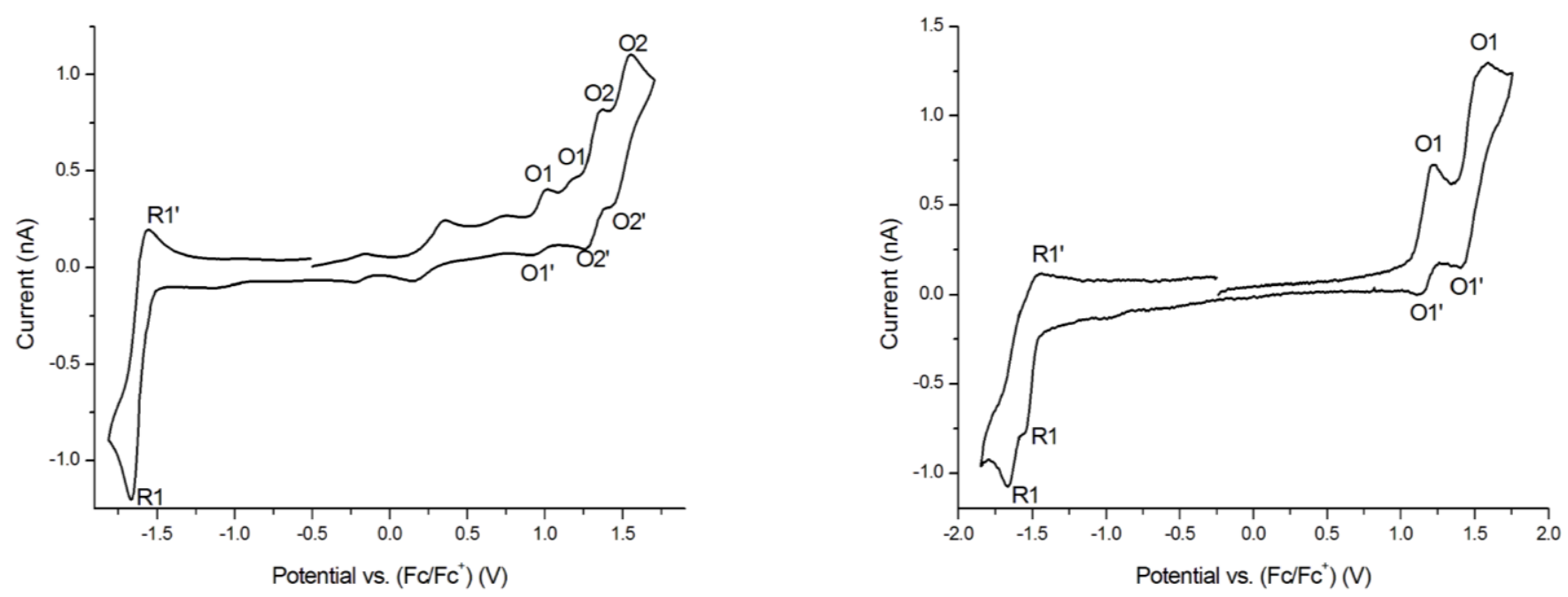

Figure 6. Voltammetric curves of $\left[\operatorname{Re}_{2} 1\right] \mathrm{PF}_{6}$ (left) and $[\mathrm{Re} 2 \mathrm{Re}] \mathrm{PF}_{6}$ (right) on a $11.8 \mu \mathrm{m}$ radius $\mathrm{Au}$ microdisk electrode in $\left[\mathrm{C}_{6} \mathrm{mim}\right][\mathrm{FAP}]$ at a scan rate of $100 \mathrm{mVs}^{-1}$. 
Table 4. Photophysical data for the prepared rhenium complexes from diluted (ca. $\left.10^{-5} \mathrm{M}\right)$ dichloromethane solutions.

\begin{tabular}{|c|c|c|c|c|c|c|c|c|}
\hline \multirow[b]{2}{*}{ Complex } & \multirow{2}{*}{$\begin{array}{c}\text { Absorption } \\
\lambda[\mathrm{nm}] \\
\left(10^{4} \varepsilon\right)\left[\mathbf{M}^{-1} \mathbf{c m}^{-1}\right]\end{array}$} & \multicolumn{5}{|c|}{ Emission 298 K } & \multicolumn{2}{|c|}{ Emission $77 \mathrm{~K}$} \\
\hline & & $\lambda[\mathrm{nm}]$ & $\begin{array}{c}\tau[\mu \mathrm{s}] \\
\text { air }\end{array}$ & $\begin{array}{c}\tau[\mu \mathrm{s}] \\
\text { dear }\end{array}$ & $\begin{array}{c}\Phi \\
\text { air }\end{array}$ & $\begin{array}{c}\Phi \\
\text { dear }\end{array}$ & $\lambda[\mathrm{nm}]$ & $\tau[\mu \mathrm{s}]$ \\
\hline$[\operatorname{Re} 1]$ & $\begin{array}{l}275(4.17) \\
359(0.44)\end{array}$ & 584 & 0.360 & 0.470 & 0.039 & 0.041 & 518 & $\begin{array}{l}3.90(21 \%) \\
8.70(79 \%)\end{array}$ \\
\hline$[\operatorname{Re} 2]$ & $\begin{array}{l}266(5.38) \\
355(0.63)\end{array}$ & 580 & 0.390 & 0.730 & 0.032 & 0.063 & 520 & 10.85 \\
\hline$[\mathrm{Re} 4] \mathrm{PF}_{6}$ & $\begin{array}{l}257(35.4) \\
337(9.54) \\
385(3.74)\end{array}$ & 540 & 1.496 & 2.866 & 0.203 & 0.490 & 504 & 7.34 \\
\hline$\left[\operatorname{Re}_{2} 1\right] \mathrm{PF}_{6}$ & $\begin{array}{c}260(35.00) \\
353(5.76)\end{array}$ & 558 & 0.898 & 2.325 & 0.068 & 0.203 & 518 & $\begin{array}{l}8.38(86 \%) \\
2.47(14 \%)\end{array}$ \\
\hline$[\mathrm{Re} 2 \mathrm{Re}] \mathrm{PF}_{6}$ & $\begin{array}{c}260(16.00) \\
328(7.05) \\
378(2.41)\end{array}$ & 557 & 0.712 & 1.217 & 0.084 & 0.246 & 520 & 7.83 \\
\hline
\end{tabular}

Photophysical properties. A summary of the photophysical data is provided in Table 4 and all the absorption, excitation and emission profiles recorded from diluted dichloromethane solutions (ca. 10 $\left.{ }^{-5} \mathrm{M}\right)$ are available in the Supplementary Information (see Figures SI6-10). The steady state absorption profiles are similar for all the prepared complexes, with differences arising from the specific nature of each complex. In general, the absorption profiles show a higher energy intense band in the 250-300 nm region tailing off into a lower energy band in the 300-450 $\mathrm{nm}$ region. The higher energy band is attributed to intraligand (IL) $\pi \rightarrow \pi^{*}$ transitions localized on the phen and tetrazolic ligands. ${ }^{11}$ On the other hand, the lower energy band is attributed to the spin allowed metal-to-ligand charge transfer (MLCT) involving the rhenium center and the coordinated aromatic ligands with accessible $\pi^{*}$ orbitals. $^{11}$

The absorption profiles for [Re1] and [Re2] are virtually identical, showing typical structureless charge transfer (CT) bands. In this case, the transition is rationalized as an admixture of metal-to-ligand and ligand-toligand $\mathrm{CT}$, the latter involving the promotion of an electron from the tetrazole ring to the $\pi^{*}$ of the phen ligand. This effect is analogous to previously studied rhenium tetrazolato complexes and the transition is better described as a metal-ligand-to-ligand charge transfer (MLLCT). ${ }^{30,51}$ 
The absorption spectrum of the cationic complex [Re4] $\mathrm{PF}_{6}$ shows an intense IL transition at $257 \mathrm{~nm}$, followed by two shoulders in the 300-400 nm region. The presence of these two bands was ascribed to two distinct MLCT processes. The lower energy one is associated to the same MLCT $\operatorname{Re} \rightarrow$ phen occurring in the neutral complexes $[\operatorname{Re} 1]$ and $[\operatorname{Re} 2]$. The shoulder at higher energy is instead associated to a MLCT process where one electron is promoted from the Re-centered orbitals to the $\pi^{*}$ system of the py, which is lowered in energy due to the coordination of the positively charged metal center to the $\mathrm{N}$ atom.

In $\left[\operatorname{Re}_{2} 1\right] \mathrm{PF}_{6}$ the two metal centers are positioned in equivalent (N1,N4 isomer) or pseudo-equivalent (N1,N3 isomer) positions, therefore sharing the overall positive charge of the complex. The direct consequence is that in $\left[\operatorname{Re}_{2} 1\right] \mathrm{PF}_{6}$ the charge on each rhenium can be considered as approximately equal to $+1 / 2$. The absorption spectrum of the dinuclear complex $\left[\operatorname{Re}_{2} 1\right] \mathrm{PF}_{6}$ shows a higher energy IL transition and a lower energy MLCT transition.

The absorption profile for the [Re2Re] $\mathrm{PF}_{6}$ complex shows higher energy IL transitions and, similarly to the spectrum of $[\operatorname{Re} 4] \mathrm{PF}_{6}$, two bands tail off in the $300-400 \mathrm{~nm}$ region. The lower energy band is ascribed to mixed MLCT transitions occurring in the two non-equivalent metal centers (of the type $\mathrm{Re} \rightarrow \mathbf{p h e n}$ ), whereas the higher energy band is attributed to the $\mathrm{Re} \rightarrow \mathbf{p y}$ charge transfer.

Following excitation to the singlet manifolds and internal conversion to the lowest excited state, the corresponding triplet manifold is rapidly populated via intersystem crossing. The radiative decay from these ${ }^{3} \mathrm{M}(\mathrm{L}) \mathrm{LCT}$ states produces broad and structureless emissions in all cases (Figure 7). ${ }^{10}$ All the complexes exhibit a monoexponential decay in solution at room temperature. The $\tau$ and $\Phi$ values in air-equilibrated and deareated solutions demonstrate that dissolved $\mathrm{O}_{2}$ causes quenching of the emissive excited states, in agreement with the phosphorescent nature of the emission from the triplet M(L)LCT excited state to the singlet ground state. The trend in the values of $\lambda_{\mathrm{em}}$ is generally in agreement with the electronic nature of the specific rhenium complex. $[\operatorname{Re} 1]$ and [Re2] have almost identical $\lambda_{\mathrm{em}}$ that are red-shifted of about $40 \mathrm{~nm}$ with respect to the emission profile of $[\mathrm{Re} 4] \mathrm{PF}_{6}$. The blue-shift of $[\mathrm{Re}] \mathrm{PF}_{6}$ can be readily explained by the wider HOMO-LUMO gap in the positively charged complex. ${ }^{30}$ For the mononuclear [Re1] and [Re2], the $\tau$ and $\Phi$ values are similar to the previously reported rhenium tetrazolato complexes. ${ }^{30}$ On the other hand, the cationic complex $[\operatorname{Re}] \mathrm{PF}_{6}$ exhibits increased $\tau$ and $\Phi$ with respect to the neutral complexes: this trend can be explained by recalling the energy gap law. ${ }^{15}$

Remarkably, $\left[\operatorname{Re}_{2} 1\right] \mathrm{PF}_{6}$ and $[\mathrm{Re} 2 \mathrm{Re}] \mathrm{PF}_{6}$ have almost superimposable emission profiles with values of $\lambda_{\mathrm{em}}$ in between the blue-shifted cationic $[\operatorname{Re} 4] \mathrm{PF}_{6}$ and the red-shifted neutral [Re1] and [Re2] complexes. The averaged $\lambda_{\mathrm{em}}$ of $\left[\operatorname{Re}_{2} 1\right] \mathrm{PF}_{6}$ can be readily interpreted following the assumption that the two metals possess an approximate charge of $+1 / 2$, therefore the HOMO-LUMO gap progressively widens in the order $[\operatorname{Re} 1] \approx\left[\operatorname{Re}_{2}\right]<\left[\operatorname{Re}_{2} 1\right] \mathrm{PF}_{6}<$ 
[Re4] $\mathrm{PF}_{6}$. The same trend is observed in the values of $\tau$ and $\Phi$ for $\left[\operatorname{Re}_{2} 1\right] \mathrm{PF}_{6}$, again in qualitative agreement with the energy gap law. ${ }^{15}$ The emission profile of $[\mathrm{Re} 2 \mathrm{Re}] \mathrm{PF}_{6}$ is independent from the excitation wavelength within the range $250-400 \mathrm{~nm}$ and is characterized by a monoexponential decay, suggesting that the radiative decay in the complex likely originates from a unique excited state localized on one of the two rhenium centers. The nature of the emissive state is again described as a ${ }^{3} \mathrm{M}(\mathrm{L}) \mathrm{LCT}$, which can be populated either by direct excitation or efficient energy transfer from the ${ }^{3} \mathrm{M}(\mathrm{L}) \mathrm{LCT}$ localized on the other rhenium center. The occurrence of efficient energy transfer is supported by the wavelength independent nature of the emission. ${ }^{25,28}$ By direct comparison with [Re2] and $[\mathrm{Re} 4] \mathrm{PF}_{6}$, the lowest excited state would seem to be located on the Re center coordinated to the tetrazole ring. However, it cannot be excluded that the coordination of a rhenium center on the tetrazole ring, as compared to an alkyl group in $[\mathrm{Re} 4] \mathrm{PF}_{6}$, favors a partial redistribution of charge leading to a shortening of the HOMO-LUMO gap for the Re coordinated to the py ring.

For all the complexes, the emission maxima at $77 \mathrm{~K}$ in a frozen matrix appear blue-shifted with respect to the values obtained at room temperature. The behaviour can be explained with the rigidochromic effect, which is responsible for raising the energy of the emissive ${ }^{3} \mathrm{M}(\mathrm{L}) \mathrm{LCT}$ due to the lack of solvent reorganisation following excitation. ${ }^{52}$ The emissive bands also show the appearance of partial vibronic coupling features, indicating some degree of mixing between ${ }^{3} \mathrm{IL}$ and ${ }^{3} \mathrm{M}(\mathrm{L}) \mathrm{LCT}$ states. ${ }^{1}$ The excited state lifetime values are significantly elongated in the frozen matrix at $77 \mathrm{~K}$ due to suppression of vibrational deactivation to the ground state.

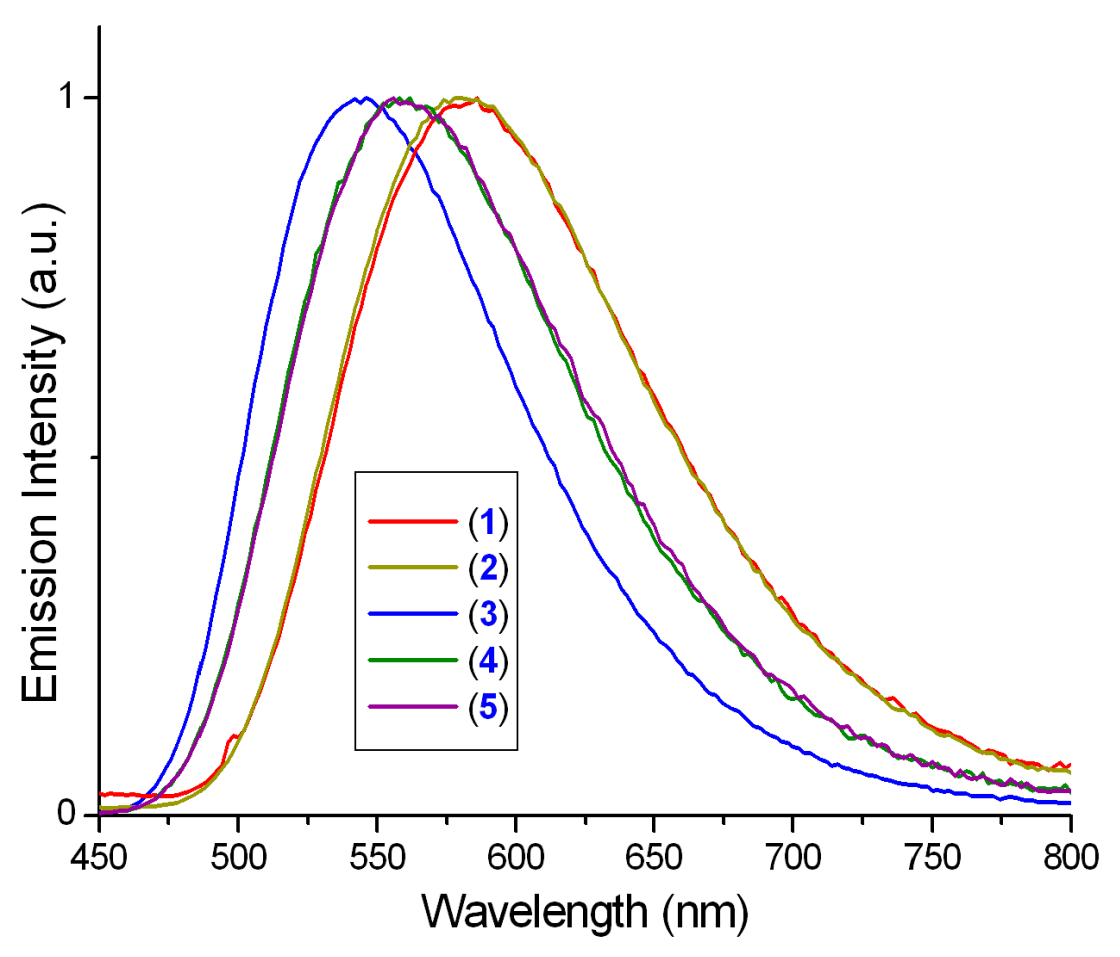


Figure 7. Normalized emission profiles for the prepared complexes: 1) [Re1]; 2) [Re2] ;3) [Re4] $\mathrm{PF}_{6}$;4)

$$
\left.\left[\operatorname{Re}_{2} 1\right] \mathrm{PF}_{6} ; 5\right)[\operatorname{Re} 2 \mathrm{Re}] \mathrm{PF}_{6} .
$$

Computational calculations. To validate the interpretation of the photophysical data the energetics and absorption spectra of the complexes were simulated with time-dependent density functional theory (TDDFT), using Gaussian 09. ${ }^{53}$ While the transitions below $300 \mathrm{~nm}$ are well understood and assigned to IL transitions, TDDFT calculations can be effectively used to help the interpretation of the M(L)LCT transitions. The overall appearance of the simulated spectra and orbital localization (see Supplementary Information Figures S11-19) is generally in good agreement with the experimental results, although a quantitative analysis reveals differences in the precise position of the peaks relative to the experimental data. This is especially noted in the [Re2] complex, for which some of the CT transitions seem to be red-shifted compared to the experimental results. These inconsistencies were explained by taking into account the limitations in the exchange-correlation description as well as the approximate nature of the implicit solvent model, ${ }^{54}$ which is used to describe the molecules of dichloromethane surrounding the complexes.

For the neutral complexes [Re1] and [Re2], the transitions occurring in the region above $300 \mathrm{~nm}$ mainly originate from charge transfer processes involving the various frontier orbitals from HOMO-1 to LUMO+2. An analysis of the major contributors to these bands reveals that the transitions originate from the promotion of an electron from metal based $5 \mathrm{~d}$ orbitals, partially mixed with the $\pi$ system of the tetrazole ring, to the $\pi^{*}$ system of either the phen or the aryl portion of the ligands $\mathbf{1}^{-}$(benzonitrile) and $\mathbf{2}^{-}$(py) respectively. These results are in agreement with the MLLCT nature attributed to these transitions. In any case, the lowest excited state is obtained via the MLLCT $(\operatorname{Re} \rightarrow$ phen $)$ transitions.

The predicted spectrum of [Re4] $\mathrm{PF}_{6}$ highlights two distinct bands above $300 \mathrm{~nm}$, which is in agreement with the experimental data. The lower energy band originates from the HOMO $\rightarrow$ LUMO transition, hence it confirms its assignment as a $\operatorname{MLCT}(\operatorname{Re} \rightarrow$ phen $)$ process contributing to the population of the emissive excited state. On the other hand, the higher energy band is associated with the HOMO $\rightarrow$ LUMO+2 transition, thus corresponding to the other MLCT $(\operatorname{Re} \rightarrow \mathbf{p y})$ that is now lowered in energy with respect to [Re2] resulting from the coordination of the py ring to the positively charged metal complex.

The predicted spectra of the $\mathrm{N} 1, \mathrm{~N} 4$ and $\mathrm{N} 1, \mathrm{~N} 3$ linkage isomers of $\left[\mathrm{Re}_{2} \mathbf{1}\right] \mathrm{PF}_{6}$ show superimposable profiles, indicating that the nature and relative energies of the electronic transitions are unaffected by the positions of the two metal centers on the tetrazole ring. In agreement with the photophysical interpretation, the orbitals involved in the electronic transitions in the region 340-400 nm range from the HOMO-3 to the LUMO+3. The HOMO-n $(\mathrm{n}=$ 
3-0) orbitals are formed by a combination of the $5 \mathrm{~d}$ orbitals on the metal centers with a minor contribution of the $\pi$ system of the tetrazole, whereas the LUMO+m $(m=0-3)$ are mainly localized on the $\pi^{*}$ system of the phen ligands. The results support the interpretation of the absorption band as an admixture of MLLCT transitions involving the two complexes.

The spectrum of the dinuclear [Re2Re] $\mathrm{PF}_{6}$ has similar features to the absorption profile of [Re4] $\mathrm{PF}_{6}$, with two close lying bands in the charge transfer region between 300 and $400 \mathrm{~nm}$. An analysis of the calculated electronic transitions reveals that the low energy band is an admixture of $\mathrm{M}(\mathrm{L}) \mathrm{LCT}$ transitions involving the 5d orbitals of the rhenium centers, the tetrazole $\pi$ system and the phen $\pi^{*}$ system. Mixed to these transitions, the theory predicts the contribution from remote $\mathrm{M}(\mathrm{L}) \mathrm{LCT}$ where one electron is promoted from the $5 \mathrm{~d}$ orbitals on the Re center to the $\pi^{*}$ orbitals the the phen ligand of the second bridged complex. These kinds of transitions were previously reported for dinuclear and trinuclear Ru complexes bridged by cyano ligands. ${ }^{55}$ Noteworthy, the lowest transition with appreciable value of oscillator strength seems to be a mixture of MLCT occurring on the Re complex coordinated to the py ring (35\%) and a remote MLLCT originating from the Re complex coordinated to the tetrazole ring (62\%). The transitions $\mathrm{HOMO} \rightarrow \mathrm{LUMO}+4$ and HOMO- $\rightarrow \mathrm{LUMO}+4$ are the main contributors to the higher energy band, and these are attributed to a remote MLLCT [Re(tetrazole) $\rightarrow \mathbf{p y}]$ and a MLCT ( $\operatorname{Re} \rightarrow \mathbf{p y})$ transfer. 


\section{Conclusions}

The coordination of rhenium fragments of the type $f a c-\left[\operatorname{Re}(\mathrm{CO})_{3}(\mathbf{p h e n})\right]^{+}$to 5-(4'-pyridyl)tetrazolate and 5(4'-cyanophenyl)tetrazolate yielded mononuclear and bridged dinuclear complexes. In the case of the mononuclear complexes, the coordination of the rhenium fragments occurs preferentially on the anionic tetrazolato ligands or, after alkylation of the tetrazole ring, on the neutral pyridine or benzonitrile substituents. The dinuclear complexes were obtained by direct coordination of the rhenium fragments to the preformed tetrazolato-bound mononuclear complexes. The structural determinations revealed, for the mononuclear complexes, the expected regioselectivity for the coordination of the metal fragments to the $\mathrm{N} 2$ atom of the tetrazole. The coordination of the metal fragment to the nitrile group of ligand $\mathbf{4}$ yielded a labile compound characterized by solvolysis of the Re-NCR bond in polar solvents. On the other hand, an unprecedented double coordination of the tetrazole ring in ligand 1 was obtained, and the resulting dinuclear complex was found to exist as an equilibrium of two linkage isomers in solution. The electrochemical behaviour evidenced reduction processes centered on the phen ligand, and oxidation processes centered on the rhenium cations with the participation of the tetrazole ring for the complexes $[\operatorname{Re} 1],[\operatorname{Re} 2]$, and $\left[\operatorname{Re}_{2} 1\right] \mathrm{PF}_{6}$. The oxidation and reduction potentials are in general good agreement with the variations in the electron density on the metal centers, however the voltammogram of $\left[\operatorname{Re}_{2} \mathbf{1}\right] \mathrm{PF}_{6}$ appears rather complicated, which is likely to be due to the equilibrating behaviour of the complex. The complexes are characterized by phosphorescent emission from their respective ${ }^{3} \mathrm{M}(\mathrm{L}) \mathrm{LCT}$ excited states. The photophysical properties of $[\operatorname{Re} 1],[\operatorname{Re} 2],[\operatorname{Re} 4] \mathrm{PF}_{6}$, and $\left[\operatorname{Re}_{2} 1\right] \mathrm{PF}_{6}$ in terms of emission maxima, excited state lifetime and quantum yield, showed trends in qualitative agreement with the energy gap law. On the other hand, the emission of the dinuclear complex $[\operatorname{Re} 2 \mathrm{Re}] \mathrm{PF}_{6} \mathrm{Seems}$ to originate from a unique excited state that is populated by efficient energy transfer between the two metal centers. Computational calculations corroborate the interpretation of the photophysical data.

\section{Experimental Section}

General remarks. All reagents and solvents were purchased from Sigma Aldrich and used as received without further purification. The room temperature ionic liquid 1-hexyl-3-methylimidazolium tris(pentafluoroethyl)trifluorophosphate $\left(\left[\mathrm{C}_{6} \mathrm{mim}\right][\mathrm{FAP}]\right)$ was purchased from Merck and used as received. THF was distilled over sodium/benzophenone according to general laboratory procedures. All procedures involving rhenium complexes were carried out under a nitrogen atmosphere using standard Schlenk techniques. Both the acidic and basic alumina for column chromatography were of Brockmann I activity unless otherwise specified. 
Alumina of Brockmann II activity was prepared by adding water to Brockmann I alumina at a ratio of $3 \% \mathrm{w} / \mathrm{w}$, shaking until clumping stopped and left in a sealed container for two days. $\mathbf{1} \mathrm{H}^{31}{ }^{31} \mathbf{2},{ }^{31} \mathbf{4},{ }^{33}$ and fac$\left[\operatorname{Re}(\mathrm{CO})_{3}(\text { phen }) \mathrm{Cl}\right]^{11}$ were prepared according to previously published procedures. Nuclear magnetic resonance spectra, consisting of ${ }^{1} \mathrm{H}$ and ${ }^{13} \mathrm{C}$ were recorded using Bruker Avance 400 spectrometer $\left(400.1 \mathrm{MHz}\right.$ for ${ }^{1} \mathrm{H}, 100$ $\mathrm{MHz}$ for ${ }^{13} \mathrm{C}$ ) at $300 \mathrm{~K} .{ }^{1} \mathrm{H}$ and ${ }^{13} \mathrm{C}$ chemical shifts were referenced to residual solvent signals. The assignment of the peaks for the phen and the various tetrazole groups are based on the referencing scheme shown below.
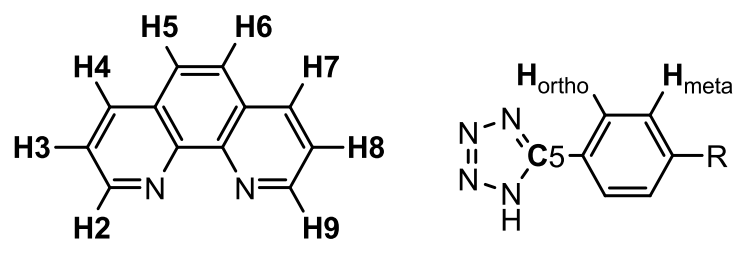

Infrared spectra were recorded in the solid state, using an attenuated total reflectance Perkin Elmer Spectrum 100 FT-IR with a diamond stage. Compounds were scanned from 4000 to $650 \mathrm{~cm}^{-1}$. The intensities of the IR bands are reported as strong (s), medium (m), or weak (w), with broad (br) bands also specified. Melting points were determined using a BI Barnsted Electrothermal 9100 apparatus and are reported uncorrected. Elemental analyses were obtained at the Central Science Laboratory, University of Tasmania, using a Thermo Finnigan EA 1112 Series Flash.

Photophysical measurements. Absorption spectra were recorded at room temperature using a Perkin Elmer Lambda $35 \mathrm{UV} / \mathrm{V}$ is spectrometer. Uncorrected steady state emission and excitation spectra were recorded on an Edinburgh FLSP920 spectrometer equipped with a $450 \mathrm{~W}$ Xenon arc lamp, double excitation and single emission monochromators and a peltier cooled Hamamatsu R928P photomultiplier tube (185-850 nm). Emission and excitation spectra were corrected for source intensity (lamp and grating) and emission spectral response (detector and grating) by a calibration curve supplied with the instrument. According to the approach described by Demas and Crosby, ${ }^{56}$ luminescence quantum yields $\left(\Phi_{\mathrm{em}}\right)$ were measured in optically dilute solutions (O.D. $<0.1$ at excitation wavelength) obtained from absorption spectra on a wavelength scale [nm] and compared to the reference emitter by the following equation:

$$
{ }_{x}=r \frac{A_{r}\left({ }_{r}\right)}{A_{x}\left({ }_{x}\right)} \frac{I_{r}\left({ }_{r}\right)}{I_{x}\left({ }_{x}\right)} \frac{n_{x}^{2}}{n_{r}^{2}} \frac{D_{x}}{D_{r}}
$$


where $A$ is the absorbance at the excitation wavelength $(\lambda), I$ is the intensity of the excitation light at the excitation wavelength $(\lambda), n$ is the refractive index of the solvent, $D$ is the integrated intensity of the luminescence and $\Phi$ is the quantum yield. The subscripts $r$ and $x$ refer to the reference and the sample, respectively. The quantum yield determinations were performed at identical excitation wavelength for the sample and the reference, therefore cancelling the $I\left(\lambda_{r}\right) / I\left(\lambda_{x}\right)$ term in the equation. All the Re complexes were measured against an air-equilibrated water solution of $\mathrm{Ru}(\mathrm{bpy}){ }_{3} \mathrm{Cl}_{2}$ used as reference $\left(\Phi_{r}=0.028\right) .{ }^{57}$ Emission lifetimes $(\tau)$ were determined with the single photon counting technique (TCSPC) with the same Edinburgh FLSP920 spectrometer using pulsed picosecond LEDs (EPLED 295 or EPLED 360, FHWM <800 ps) as the excitation source, with repetition rates between $10 \mathrm{kHz}$ and $1 \mathrm{MHz}$, and the above-mentioned R928P PMT as detector. The goodness of fit was assessed by minimizing the reduced $\chi^{2}$ function and by visual inspection of the weighted residuals. To record the $77 \mathrm{~K}$ luminescence spectra, the samples were put in quartz tubes ( $2 \mathrm{~mm}$ diameter) and inserted in a special quartz dewar filled up with liquid nitrogen. The solvent (dichloromethane) used in the preparation of the solutions for the photophysical investigations were of spectrometric grade. All the prepared solutions were filtered through a $0.2 \mu \mathrm{m}$ syringe filter before measurement. Degassed solutions were prepared by the freeze-pump-thaw technique. Experimental uncertainties are estimated to be $\pm 8 \%$ for lifetime determinations, $\pm 20 \%$ for quantum yields, $\pm 2 \mathrm{~nm}$ and $\pm 5 \mathrm{~nm}$ for absorption and emission peaks, respectively.

Electrochemical measurements. A gold microelectrode (made in house and kindly donated by the group of Professor Richard Compton at Oxford University, UK) was polished and modified with a section of disposable micropipette tip into which microlitre quantities of the ionic liquid solvent can be placed. The electrode was then inserted into a "T-cell" apparatus as described elsewhere. ${ }^{58}$ A silver wire $(0.5 \mathrm{~mm}$ diameter $)$ was inserted from the top and acted as a combined counter and reference electrode. The T-cell was placed inside an aluminium Faraday cage and connected to a vacuum pump (Edwards ES50). The samples for electrochemistry were prepared by dissolving the required amount of rhenium complex in a minimal amount of DCM and then adding this solution to the ionic liquid (1-hexyl-3-methylimidazolium tris(pentafluoroethyl)trifluorophosphate) in order to obtain a final concentration of the order of $10 \mathrm{mM}$. The solution was left in an open container to allow the DCM to evaporate. 40 $\mu \mathrm{L}$ of this sample were transferred into the T-cell with the use of a micropipette. Experiments requiring the use of ferrocene followed the above procedure, however $10 \mu \mathrm{L}$ of a $10 \mathrm{mM}$ solution of ferrocene in acetonitrile was added into the T-cell apparatus along with the ionic liquid containing the rhenium complex. Cyclic voltammetry experiments were performed using a PGSTAT302N potentiostat (Eco-Chemie, Netherlands) interfaced to a PC 
with GPES (General Purpose Electrochemical System) software. The step potential was fixed at $0.01 \mathrm{~V}$. The potentials are referenced to an internal reference Ferrocene/Ferrocenium redox couple according to IUPAC recommendations, ${ }^{59}$ and established in ionic liquids. ${ }^{49,60}$ Scans were performed using a potential window within the range of $-1.7-2.5 \mathrm{~V}$ reliant on the compound investigated. Reported oxidation and reduction potentials were obtained from a scan rate of $100 \mathrm{mVs}^{-1}$.

Computational calculations. Time dependent density functional theory calculations were performed with GAUSSIAN $09^{53}$ in order to calculate the absorption spectra of all compounds. Prior to these calculations the structures were relaxed at the 6-311 $\mathrm{g}^{* *}$ level of theory. Re atoms were treated with the Stuttgart-Dresden (SDD) Effective Core Potential ${ }^{61}$ and the effect of the solvent was mimicked with the PCM solvation model. ${ }^{54}$ The low lying singlet-singlet excitation energies were calculated at the same level of theory and the spectra were reproduced as the superposition of Gaussian functions with heights proportional to the calculated intensities and a variance of $11 \mathrm{~nm}$.

Synthesis of 3. Potassium carbonate $(0.13 \mathrm{~g}, 1 \mathrm{mmol})$, benzyl bromide $(0.20 \mathrm{~g}, 1 \mathrm{mmol})$ and $\mathbf{1 H}(0.19 \mathrm{~g}, 1$ mmol) were combined in acetone $(20 \mathrm{~mL})$ and stirred at reflux for $24 \mathrm{hrs}$. The reaction was cooled and the solvent was reduced; the resulting solid was dissolved in DCM and extracted with 5\% sodium carbonate solution, water, and brine (each for $20 \mathrm{~mL}$ ). The organic phase was collected, dried over magnesium sulphate and the solvent was removed under vacuum. The resulting solid was recrystallised from hexanes yielding a white solid. Yield: $0.145 \mathrm{~g}$ (56\%); m.p. $112{ }^{\circ} \mathrm{C}$ (dec.); ${ }^{1} \mathrm{H}$ NMR $\left(\mathrm{CDCl}_{3}\right): \delta=8.25\left(\mathrm{~d},{ }^{3} J(\mathrm{H}, \mathrm{H})=8.4 \mathrm{~Hz}, 2 \mathrm{H} ; \mathbf{H}_{\text {meta }}\right), 7.75\left(\mathrm{~d},{ }^{3} J(\mathrm{H}, \mathrm{H})=8.4 \mathrm{~Hz}\right.$, $2 \mathrm{H} ; \mathbf{H}_{\text {ortho}}$ ), 7.41-7.26 (m, 5H; Ph-H), 5.82 (s, 2H; $\left.\mathrm{CH}_{2}\right) \mathrm{ppm} ;{ }^{13} \mathrm{C} \mathrm{NMR}\left(\mathrm{CDCl}_{3}\right): \delta=164.0(\mathbf{C} 5), 133.0,132.8$, 131.7, 129.3, 129.2, 128.6, 126.5, 118.5, 114.0 ppm; IR: $v_{\max }=2996 \mathrm{w}\left(\mathrm{sp}^{3} \mathrm{CH}\right), 2230 \mathrm{~s}(\mathrm{CN}), 1496 \mathrm{~m}, 1464 \mathrm{~s}$, $1456 \mathrm{~s}, 1438 \mathrm{~m}, 1423 \mathrm{~m}, 1340 \mathrm{~m}, 1202 \mathrm{~m}, 1043 \mathrm{~m}, 856 \mathrm{~m} \mathrm{~cm}^{-1}$; elemental analysis calcd (\%) for 3: C 68.95, H 4.24, N 26.80; found: C 69.05, H 4.01, N 26.71.

Synthesis of [Re1]. $1 \mathrm{H}(0.07 \mathrm{~g}, 0.4 \mathrm{mmol})$ was combined with triethylamine $(55 \mu \mathrm{L}, 0.4 \mathrm{mmol})$ in $10 \mathrm{~mL}$ acetonitrile and $f a c-\left[\operatorname{Re}(\mathrm{CO})_{3}(\right.$ phen $\left.) \mathrm{Cl}\right](0.10 \mathrm{~g}, 0.2 \mathrm{mmol})$ was added to the solution. The solution was stirred at reflux for 48 hours, then allowed to cool to room temperature. The solvent was removed and the solid was purified via column chromatography with acidic alumina as the stationary phase using dichloromethane/ethyl acetate (4:1) solvent system as the eluent to elute the first fraction and a 5:1 toluene/ethanol mixture to elute the second fraction. The first fraction was collected and identified as unreacted starting material, the second fraction was collected and 
the solvent was removed to yield a bright yellow solid. Single crystals suitable for X-ray diffraction were grown from a slowly evaporating solution of $[\mathrm{Re} 1]$ in chloroform. Yield: $64 \mathrm{mg}(51 \%)$; m.p. $258{ }^{\circ} \mathrm{C}$ (dec.). ${ }^{1} \mathrm{H} \mathrm{NMR}$ ([D $\left.\left.]_{6}\right] \mathrm{DSO}\right): \delta=9.57\left(\mathrm{~d},{ }^{3} J(\mathrm{H}, \mathrm{H})=5.2 \mathrm{~Hz}, 2 \mathrm{H} ; \mathbf{H} 2 \mathbf{H} 9\right), 8.99\left(\mathrm{~d},{ }^{3} J(\mathrm{H}, \mathrm{H})=8.2 \mathrm{~Hz}, 2 \mathrm{H} ; \mathbf{H} 4 \mathbf{H} 7\right), 8.31(\mathrm{~s}, 2 \mathrm{H} ; \mathbf{H} 5$ H6), 8.15-8.11 (m, 2H; H3 H8), $7.75\left(\mathrm{~d},{ }^{3} J(\mathrm{H}, \mathrm{H})=8.8 \mathrm{~Hz}, 2 \mathrm{H} ; \mathbf{H}_{\text {meta }}\right), 7.67$ (d, ${ }^{3} J(\mathrm{H}, \mathrm{H})=8.8 \mathrm{~Hz}, 2 \mathrm{H}$; $\left.\mathbf{H}_{\text {ortho }}\right)$ ppm; ${ }^{13} \mathrm{C}$ NMR ([D $]$ DMSO): $\delta=161.1$ (C5), 154.4, 146.4, 139.8, 133.3, 132.8, 130.3, 127.8, 126.8, 126.0, 118.6 ppm; IR: $v_{\max }=2923 \mathrm{w}, 2228 \mathrm{~m}(\mathrm{CN}), 2017 \mathrm{~s}\left(\mathrm{CO} \mathrm{A}^{\prime}(1)\right), 1912 \mathrm{~s}\left(\mathrm{CO} \mathrm{A}^{\prime}(2)\right), 1896 \mathrm{~s}\left(\mathrm{CO} \mathrm{A}^{\prime}\right), 1615 \mathrm{w}, 1521 \mathrm{w}, 1430 \mathrm{w}$, 1417 w, 1248 w, 1042 w, $846 \mathrm{~m} \mathrm{~cm}^{-1}$; elemental analysis calcd $(\%)$ for $[\operatorname{Re} 1] \cdot\left(\mathrm{C}_{6} \mathrm{H}_{5} \mathrm{Me}\right)_{1 / 4}(\mathrm{EtOH})_{1 / 4}: \mathrm{C} 46.29, \mathrm{H}$ 2.38, N 14.97; found: C 46.29, H 2.27, N 14.76.

Synthesis of [Re2]. $2 \mathrm{H}(0.09 \mathrm{~g}, 0.6 \mathrm{mmol})$ was combined with triethylamine $(83 \mu \mathrm{L}, 0.6 \mathrm{mmol})$ in $10 \mathrm{~mL}$ acetonitrile and $f a c-\left[\operatorname{Re}(\mathrm{CO})_{3}(\right.$ phen $\left.) \mathrm{Cl}\right](0.15 \mathrm{~g}, 0.3 \mathrm{mmol})$ was added to the solution and stirred at reflux for 48 hours. The solution was then allowed to cool to room temperature and the solvent was evaporated under reduced pressure. The solid was dissolved in the minimal amount of dichloromethane and purified by column chromatography using basic alumina as the stationary phase and a mixture of dichloromethane and ethyl acetate (4:1) as the eluent. The first fraction was collected and identified as unreacted $f a c-\left[\operatorname{Re}(\mathrm{CO})_{3}(\mathbf{p h e n}) \mathrm{Cl}\right]$. The second fraction was collected and the solvent was removed to give a yellow solid. Single crystals suitable for X-ray diffraction were grown from a slowly evaporating solution of [Re2] in chloroform. Yield: 0.105 g (59\%); m.p. 270 ${ }^{\circ} \mathrm{C}$ (dec.). ${ }^{1} \mathrm{H}$ NMR ([D 6$]$ DMSO): $\delta=9.57\left(\mathrm{~d},{ }^{3} J(\mathrm{H}, \mathrm{H})=5.3 \mathrm{~Hz}, 2 \mathrm{H} ; \mathbf{H} 2 \mathbf{H} 9\right), 9.00\left(\mathrm{~d},{ }^{3} J(\mathrm{H}, \mathrm{H})=8.4 \mathrm{~Hz}, 2 \mathrm{H} ; \mathbf{H} 4\right.$ H7), $8.48\left(\mathrm{~d},{ }^{3} J(\mathrm{H}, \mathrm{H})=6.4 \mathrm{~Hz}, 2 \mathrm{H} ; \mathbf{H}_{\text {meta }}\right), 8.31$ (s, 2H; H5 H6), 8.11-8.14 (m, 2H; H3 H8), $7.42\left(\mathrm{~d},{ }^{3} J(\mathrm{H}, \mathrm{H})=6.4\right.$ $\mathrm{Hz}, 2 \mathrm{H} ; \mathbf{H}_{\text {ortho }}$ ) ppm; ${ }^{13} \mathrm{C}$ NMR ([D $]$ DMSO): $\delta=196.3$ (CO), 193.4 (CO), 160.6 (C5), 154.3, 150.2, 146.5, 139.9, 136.1, 130.3, 127.8, 126.8, 119.7 ppm; IR: $v_{\max }=2853$ w, 2020 (CO A'(1)) s, 1898 (CO A'(2) \& A"), 1609 m, 1520 m, $1429 \mathrm{~m}, 1415 \mathrm{~m}, 1039 \mathrm{w}, 849 \mathrm{~m} \mathrm{~cm}^{-1}$; elemental analysis calcd $(\%)$ for $[\mathrm{Re} 2] \cdot\left(\mathrm{CH}_{3} \mathrm{CO}_{2} \mathrm{Et}\right)_{1 / 3}: \mathrm{C} 42.85, \mathrm{H} \mathrm{2.36}$, N 15.89; found: C 42.98, H 2.00, N 15.91.

Synthesis of [Re4]PF 6 . $f a c-\left[\operatorname{Re}(\mathrm{CO})_{3}(\right.$ phen $\left.) \mathrm{Cl}\right](0.10 \mathrm{~g}, 0.2 \mathrm{mmol})$ and $\mathrm{AgSO}_{3} \mathrm{CF}_{3}(0.05 \mathrm{~g}, 0.2 \mathrm{mmol})$ were combined in dry THF ( $5 \mathrm{~mL}$ ), while shielded from light and under nitrogen atmosphere, and heated at reflux for 4 hours. To this mixture, $3(0.04 \mathrm{~g}, 0.2 \mathrm{mmol})$ was added and the mixture was stirred at reflux for 24 hours. The reaction mixture was cooled and filtered through celite, the solution reduced in volume, and $1 \mathrm{~mL}$ of methanol was added. This mixture was added to $2 \mathrm{~mL}$ of methanol containing $0.3 \mathrm{~g}$ of $\mathrm{NH}_{4} \mathrm{PF}_{6}$. The solid formed was filtered and redissolved in dichloromethane and purified by column chromatography using acidic alumina as the stationary phase and a mixture of dichloromethane/ethyl acetate $(4: 1)$ as the eluent. The first fraction was collected and 
identified as unreacted $f a c$ - $\left[\operatorname{Re}(\mathrm{CO})_{3}(\right.$ phen $\left.) \mathrm{Cl}\right]$. The second fraction was collected, the solvent volume reduced, and diethyl ether was added to precipitate the yellow solid. Single crystals suitable for X-ray diffraction were grown from layering hexanes on a DCM solution of [Re4]PF . Yield $32 \mathrm{mg}(20 \%)$; m.p. $165{ }^{\circ} \mathrm{C}$ (dec.); ${ }^{1} \mathrm{H}$ NMR $\left(\mathrm{CD}_{3} \mathrm{CN}\right): \delta=9.66\left(\mathrm{~d},{ }^{3} J(\mathrm{H}, \mathrm{H})=5.2 \mathrm{~Hz}, 2 \mathrm{H} ; \mathbf{H} 2 \mathbf{H} 9\right), 8.89\left(\mathrm{~d},{ }^{3} J(\mathrm{H}, \mathrm{H})=8.4 \mathrm{~Hz}, 2 \mathrm{H} ; \mathbf{H} 4 \mathbf{H} 7\right), 8.45\left(\mathrm{~d},{ }^{3} J(\mathrm{H}, \mathrm{H})=5.4\right.$ $\left.\mathrm{Hz}, 2 \mathrm{H} ; \mathbf{H}_{\text {meta }}\right), 8.20$ (s, 2H; H5 H6), 7.79 (d, ${ }^{3} J(\mathrm{H}, \mathrm{H})=5.4 \mathrm{~Hz}, 2 \mathrm{H} ; \mathbf{H}_{\text {ortho }}$ ), 1.68 (s, 9H; $\left.\mathrm{CH}_{3}\right)$ ppm; ${ }^{13} \mathrm{C} \mathrm{NMR}$ $\left(\mathrm{CD}_{3} \mathrm{CN}\right): \delta=196.8,192.4,161.5$ (C5), 155.6, 154.0, 147.5, 141.4, 139.1, 132.3, 129.1, 128.1, $128.9,66.0$ $\left.\left(\mathrm{CCH}_{3}\right)_{3}\right), 29.3\left(\mathrm{CH}_{3}\right)$ ppm; IR: $v_{\max }=2924 \mathrm{w}\left(\mathrm{CH}_{3}\right), 2853 \mathrm{w}\left(\mathrm{CH}_{3}\right), 2030 \mathrm{~s}\left(\mathrm{CO} \mathrm{A}^{\prime}(1)\right), 1906 \mathrm{~s}\left(\mathrm{CO} \mathrm{A}^{\prime}(2) \& \mathrm{~A}^{\prime \prime}\right)$, 1708 w, 1627 w, 1522 w, 1460 w, 1431 m, 1222 w, 1046 w, 1028 w, 1212 w, $828 \mathrm{~m} \mathrm{~cm}^{-1}$; elemental analysis calcd (\%) for [Re4]PF 6 : C 37.60, H 2.65, N 12.28; found: C 37.77, H 2.48, N 12.11.

Synthesis of $\left[\mathbf{R e}_{2} \mathbf{1}\right] \mathbf{P F}_{\mathbf{6}}$. $f a c-\left[\operatorname{Re}(\mathrm{CO})_{3}(\mathbf{p h e n}) \mathrm{Cl}\right](0.04 \mathrm{~g}, 0.08 \mathrm{mmol})$ and $\mathrm{AgSO}_{3} \mathrm{CF}_{3}(0.02 \mathrm{~g}, 0.08 \mathrm{mmol})$ were combined in dry THF $(5 \mathrm{~mL})$, while shielded from light and under nitrogen atmosphere, and heated at reflux for 4 hours. To the mixture, [Re1] $(0.05 \mathrm{mg}, 0.08 \mathrm{mmol})$ was added and the mixture was stirred at reflux for 24 hours. The reaction mixture was cooled, filtered through celite, the solvent removed, and $1 \mathrm{~mL}$ of methanol was added. This solution was added to $2 \mathrm{~mL}$ of methanol containing $0.3 \mathrm{~g} \mathrm{NH}_{4} \mathrm{PF}_{6}$. The solid formed was purified by column chromatography using Brockmann II acidic alumina as the stationary phase and a mixture of dichloromethane/ethyl acetate (4:1) was used to elute any unreacted $f a c$ - $\left[\operatorname{Re}(\mathrm{CO})_{3}(\mathrm{phen}) \mathrm{Cl}\right]$ as the first fraction. A mixture of ethyl acetate/acetonitrile (4:1) was used to elute the second fraction, which was collected, the solvent volume reduced, and diethyl ether was added to precipitate the yellow solid. Single crystals suitable for X-ray diffraction were grown from layering hexanes on a DCM solution of $\left[\mathrm{Re}_{2} 1\right] \mathrm{PF}_{6}$. Yield: $25 \mathrm{mg}(26 \%)$; m.p. $130{ }^{\circ} \mathrm{C}$ (dec.); ${ }^{1} \mathrm{H}$ NMR $\left(\mathrm{CDCl}_{3}\right): \delta=8.96\left(\mathrm{~d},{ }^{3} J(\mathrm{H}, \mathrm{H})=4.7 \mathrm{~Hz}, 2 \mathrm{H} ; \mathbf{H} 2 \mathbf{H} 9\right), 8.87\left(\mathrm{~d},{ }^{3} J(\mathrm{H}, \mathrm{H})=5.5 \mathrm{~Hz}, 2 \mathrm{H} ; \mathbf{H} 2 \mathbf{H} 9\right), 8.80$ $\left(\mathrm{d},{ }^{3} \mathrm{~J}(\mathrm{H}, \mathrm{H})=8.2 \mathrm{~Hz}, 2 \mathrm{H} ; \mathbf{H} 4 \mathbf{H} 7\right), 8.65\left(\mathrm{~d},{ }^{3} \mathrm{~J}(\mathrm{H}, \mathrm{H})=8.2 \mathrm{~Hz}, 2 \mathrm{H} ; \mathbf{H} 4 \mathbf{H} 7\right), 8.27$ (s, 2H; H5 H6), 8.03 (s, 2H; H5 H6), 7.89-7.84 (m, 4H; H3 H8 x 2), $7.62\left(\mathrm{~d},{ }^{3} J(\mathrm{H}, \mathrm{H})=8.4 \mathrm{~Hz}, 2 \mathrm{H} ; \mathbf{H}_{\text {meta }}\right), 7.19\left(\mathrm{~d},{ }^{3} J(\mathrm{H}, \mathrm{H})=8.4 \mathrm{~Hz}, 2 \mathrm{H} ; \mathbf{H}_{\text {ortho }}\right)$ ppm; ${ }^{13} \mathrm{C}$ NMR ([D $]$ ACETONE): 155.2, 147.7, 140.9, 140.6, 133.2, 131.8, 130.9, 128.9, 127.5 ppm; IR: $v_{\max }=$ 2970 w, $2233.1 \mathrm{w}(\mathrm{CN}), 2027 \mathrm{~s}\left(\mathrm{CO} \mathrm{A}^{\prime}(1)\right), 1906 \mathrm{~s}$ (CO A'(2) \& A"), $1633 \mathrm{w}, 1521 \mathrm{w}, 1430 \mathrm{w}, 838 \mathrm{~m} \mathrm{~cm}^{-1}$; elemental analysis calcd (\%) for [ $\left.\operatorname{Re}_{2} 1\right] \mathrm{PF}_{6}$ : C 37.53, H 1.66, N 10.19; found: C 37.49, H 1.49, N 10.19.

Synthesis of [Re2Re]PF 6 . $f a c$ - $\left[\operatorname{Re}(\mathrm{CO})_{3}(\mathbf{p h e n}) \mathrm{Cl}\right](0.04 \mathrm{~g}, 0.08 \mathrm{mmol})$ and $\mathrm{AgSO}_{3} \mathrm{CF}_{3}(0.02 \mathrm{~g}, 0.08 \mathrm{mmol})$ were combined in dry THF $(5 \mathrm{~mL})$, while shielded from light and under nitrogen atmosphere, and heated at reflux for 4 hours. To this mixture, [Re2] (0.05 g, $0.08 \mathrm{mmol})$ was added and the mixture was stirred at reflux for 24 hours. The reaction mixture was cooled to room temperature and filtered through celite. The solution was reduced 
in volume and $1 \mathrm{~mL}$ of methanol was added. This mixture was added to $2 \mathrm{~mL}$ of methanol containing $0.3 \mathrm{~g}$ $\mathrm{NH}_{4} \mathrm{PF}_{6}$. The solid formed was purified by column chromatography using Brockmann II basic alumina as the stationary phase. A mixture of dichloromethane/ethyl acetate (4:1) was used to elute any unreacted fac$\operatorname{Re}(\mathrm{CO})_{3}$ (phen) $\mathrm{Cl}$ as the first fraction. A mixture of ethyl acetate/acetonitrile (1:1) was used to elute the second fraction, which was collected, the solvent volume reduced, and diethyl ether was added to precipitate the yellow solid. Single crystals suitable for X-ray diffraction were grown from layering hexanes on a DCM solution of [Re2Re]PF . Yield: $20 \mathrm{mg}(20 \%)$; m.p. $212{ }^{\circ} \mathrm{C}$ (dec.); ${ }^{1} \mathrm{H}$ NMR $\left(\mathrm{CD}_{3} \mathrm{CN}\right): \delta=9.54\left(\mathrm{~d},{ }^{3} J(\mathrm{H}, \mathrm{H})=5.2 \mathrm{~Hz}, 2 \mathrm{H} ; \mathbf{H} 2\right.$ H9), $9.41\left(\mathrm{~d},{ }^{3} J(\mathrm{H}, \mathrm{H})=5.2 \mathrm{~Hz}, 2 \mathrm{H} ; \mathbf{H} 2 \mathbf{H} 9\right), 8.79\left(\mathrm{~d},{ }^{3} J(\mathrm{H}, \mathrm{H})=8.4 \mathrm{~Hz}, 2 \mathrm{H} ; \mathbf{H} 4 \mathbf{H} 7\right), 8.70\left(\mathrm{~d},{ }^{3} J(\mathrm{H}, \mathrm{H})=8.2 \mathrm{~Hz}, 2 \mathrm{H}\right.$;

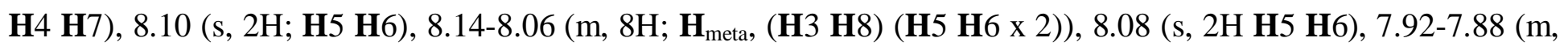
2H; H3 H8), 7.27 (d, $\left.{ }^{3} J(\mathrm{H}, \mathrm{H})=5.4 \mathrm{~Hz}, 2 \mathrm{H} ; \mathbf{H}_{\text {ortho }}\right) \mathrm{ppm} ;{ }^{13} \mathrm{C} \mathrm{NMR}\left(\mathrm{CD}_{3} \mathrm{CN}\right): \delta=197.8(\mathbf{C O}), 196.6(\mathbf{C O}), 160.5$ (C5), 155.3, 155.0, 153.2, 184.1, 147.5, 141.2, 140.8, 140.4, 132.2, 131.6, 129.0, 128.6, 128.0, 127.2, 123.1 ppm; IR $v_{\max }=3096 \mathrm{w}, 2025 \mathrm{~s}\left(\mathrm{CO} \mathrm{A}^{\prime}(1)\right), 1895 \mathrm{~s}\left(\mathrm{CO} \mathrm{A}^{\prime}(2) \& \mathrm{~A}^{\prime \prime}\right), 1622 \mathrm{w}, 1520 \mathrm{w}, 1429 \mathrm{~m}, 1224 \mathrm{w}, 1148 \mathrm{w}, 1110 \mathrm{w}$, $1042 \mathrm{w}, 1012 \mathrm{w}, 835 \mathrm{w} \mathrm{cm}^{-1}$; elemental analysis calcd (\%) for [Re2Re]PF 6 : C 36.27, H 1.69, N 10.58; found: C $36.48, \mathrm{H} 1.45, \mathrm{~N} 10.42$.

X-ray crystallography. Crystallographic data for the structures were collected at 100(2) K on an Oxford Diffraction Gemini ([Re4] $\left.\mathrm{PF}_{6},\left[\mathrm{Re}_{2} 1\right] \mathrm{PF}_{6},[\mathrm{Re} 2 \mathrm{Re}] \mathrm{PF}_{6}\right)$ or Oxford Diffraction Xcalibur diffractometer ([Re1] and [Re2]) fitted with Mo K $\alpha$ radiation $(\lambda=0.71073 \AA)$. Following analytical absorption corrections and solution by direct methods, the structures were refined against $F^{2}$ with full-matrix least-squares using the program SHELXL97. ${ }^{62}$ All hydrogen atoms were added at calculated positions and refined by use of a riding model with isotropic displacement parameters based on those of the parent atoms. The crystal structures are depicted in Figures 9-13 where displacement ellipsoids are drawn at the 50\% confident level and with hydrogen atoms omitted.

Crystal data and structure refinement for [Re1]: Empirical formula $\mathrm{C}_{24.50} \mathrm{H}_{13.50} \mathrm{Cl}_{4.50} \mathrm{~N}_{7} \mathrm{O}_{3} \operatorname{Re} . M W=$ 799.65. Orthorhombic, space group Pbca, $a=12.5208(2), b=18.2828(3), c=24.9107(5) \AA, V=5702.44(17) \AA^{3}$, $Z=8, \rho_{\mathrm{C}} 1.863 \mathrm{~g} \mathrm{~cm}^{-3}, \mu=4.724 \mathrm{~mm}^{-1}$. Crystal size $=0.54 \times 0.46 \times 0.06 \mathrm{~mm}^{3}$. Reflections collected $=200961$, unique reflections $=18207[R(\mathrm{int})=0.0610]$. Max. and min. transmission $=0.769$ and 0.172 . No. parameters $=$ 407. $\mathrm{GoF}=1.052$. Final $R$ indices $[I>2 \sigma(I)] R 1=0.0437, w R 2=0.0966 . R$ indices (all data) $R 1=0.0628, w R 2=$ 0.1026. Largest diff. peak and hole $=4.250$ and -2.189 e $\AA^{-3}$. Both $\mathrm{CHCl}_{3}$ solvent molecules were modelled as being disordered. The site occupancies for the two sets of chlorine atoms for molecule 1 refined to $0.686(3)$ and its complement. Solvent molecule 2 is disordered about a crystallographic inversion center. 
Crystal data and structure refinement for [Re2]: Empirical formula $\mathrm{C}_{21} \mathrm{H}_{12} \mathrm{~N}_{7} \mathrm{O}_{3} \mathrm{Re} . M W=596.58$. Monoclinic, space group $C 2 / c, a=20.3187(6), b=8.6848(5), c=24.4550(7) \AA, \beta=108.812(3)^{\circ}, V=4084.9(3)$ $\AA^{3}, Z=8, \rho_{\mathrm{C}}=1.940 \mathrm{~g} \mathrm{~cm}^{-3}, \mu=5.990 \mathrm{~mm}^{-1}$. Crystal size $=0.25 \times 0.17 \times 0.14 \mathrm{~mm}^{3}$. Reflections measured $=$ 31770 , unique reflections $=9254[R($ int $)=0.0421]$. Max. and min. transmission $=0.543$ and 0.392. No. parameters $=289 . \mathrm{GoF}=0.858$. Final $R$ indices $[I>2 \sigma(I)] R_{1}=0.0267, w R_{2}=0.0510 . R$ indices (all data) $R_{1}=0.0411, w R_{2}=$ 0.0525. Largest diff. peak and hole $=2.218$ and -0.995 e $\AA^{-3}$.

Crystal data and structure refinement for [Re4]PF $:$ Empirical formula $\mathrm{C}_{25} \mathrm{H}_{21} \mathrm{~F}_{6} \mathrm{~N}_{7} \mathrm{O}_{3} \mathrm{PRe}$. $M W=$ 798.66. Monoclinic, space group $P 2{ }_{1} / n, a=11.5325(3), b=14.9990(5), c=16.5483(4) \AA, \beta=95.276(2)^{\circ}, V=$ 2850.33(14) $\AA^{3}, Z=4, \rho_{\mathrm{C}}=1.861 \mathrm{~g} \mathrm{~cm}^{-3}, \mu=4.400 \mathrm{~mm}^{-1}$. Crystal size $=0.55 \times 0.10 \times 0.10 \mathrm{~mm}^{3}$. Reflections measured $=36589$, unique reflections $=9893[R($ int $)=0.0645]$. Max. and min. transmission $=0.682$ and 0.254 . No. parameters $=391$. GoF $=0.861$. Final $R$ indices $[I>2 \sigma(I)] R 1=0.0337, w R 2=0.0555 . R$ indices (all data) $R 1=$ $0.0677, w R 2=0.0591$. Largest diff. peak and hole $=1.606$ and $-1.298 \mathrm{e}^{-3}$.

Crystal data and structure refinement for $\left[\mathbf{R e}_{\mathbf{2}} \mathbf{1}\right] \mathbf{P F}_{\mathbf{6}}$ : Empirical formula $\mathrm{C}_{41} \mathrm{H}_{26} \mathrm{~F}_{6} \mathrm{~N}_{9} \mathrm{O}_{7} \mathrm{PRe}_{2} . M W=$ 1274.08. Triclinic, space group $P \overline{1}, a=11.276(5), b=13.079(5), c=14.516(5) \AA, \alpha=92.170(5), \beta=92.134(5), \gamma=$ 99.976(5) ${ }^{\circ}, V=2104.8(14) \AA^{3}, Z=2, \rho_{\mathrm{C}}=2.010 \mathrm{~g} \mathrm{~cm}^{-3}, \mu=5.873 \mathrm{~mm}^{-1}$. Crystal size $=0.75 \times 0.44 \times 0.02 \mathrm{~mm}^{3}$. Reflections measured $=51348$, unique reflections $=15841[R($ int $)=0.0528]$. Max. and min. transmission $=0.886$ and 0.088. No. parameters $=629 . \mathrm{GoF}=1.064$. Final $R$ indices $[I>2 \sigma(I)] R 1=0.0497, w R 2=0.1099$. $R$ indices (all data) $R 1=0.0794, w R 2=0.1192$. Largest diff. peak and hole $=4.020$ and $-3.252 \mathrm{e} \AA^{-3}$. The solvent was modelled as a molecule of acetone disordered over two sets of sites with equal occupancies.

Crystal data and structure refinement for [Re2Re]PF $\mathbf{P F}_{6}$ Empirical formula $\mathrm{C}_{38.50} \mathrm{H}_{25} \mathrm{Cl}_{5} \mathrm{~F}_{6} \mathrm{~N}_{9} \mathrm{O}_{6} \mathrm{PRe}_{2}$. $M W=1404.30$. Triclinic, space group $P \overline{1}, a=13.5106(11), b=13.9668(12), c=14.3512(10) \AA, \alpha=72.813(7), \beta=$ 63.262(8), $\gamma=75.253(7)^{\circ}, V=2286.9(3) \AA^{3}, Z=2, \rho_{C}=2.039 \mathrm{~g} \mathrm{~cm}^{-3}, \mu=5.697 \mathrm{~mm}^{-1}$. Crystal size $=0.45 \mathrm{x} 0.06 \mathrm{x}$ $0.02 \mathrm{~mm}^{3}$. Reflections measured $=18329$, unique reflections $=8496[R(\mathrm{int})=0.0957]$. Max. and min. transmission $=0.933$ and 0.608. No. parameters $=640 . \mathrm{GoF}=0.803$. Final $R$ indices $[I>2 \sigma(I)] R 1=0.0593, w R 2=0.1044 . R$ indices (all data) $R 1=0.1446, w R 2=0.1165$. Largest diff. peak and hole $=2.271$ and $-1.034 \mathrm{e} \AA^{-3}$. The solvent was modelled as three molecules of dichloromethane, of which one was disordered about a crystallographic inversion center and another disordered over two sites with occupancies constrained to 0.5 after trial refinement. 


\section{Supplementary Information}

Detailed NMR studies. Bond lengths and angle values for the crystallographically characterized complexes. Cyclic voltammograms for the mononuclear complexes. Detailed absorption, excitation and emission profiles for all the complexes. TDDFT-simulated absorption profiles, list of electronic transitions and molecular orbital representations for all the complexes. Full details of the structure determinations (except structure factors) have been deposited with the Cambridge Crystallographic Data Center as CCDC 882648 ([Re1]), 882649 ([Re2]), $882650\left([\operatorname{Re} 4] \mathrm{PF}_{6}\right), 882651\left(\left[\operatorname{Re}_{2} 1\right] \mathrm{PF}_{6}\right), 882652\left([\operatorname{Re} 2 \mathrm{Re}] \mathrm{PF}_{6}\right)$. Copies of this information may be obtained free of charge from The Director, CCDC, 12 Union Road, Cambridge CB2 1EZ, UK (Fax: + 441223 336 033 ; e-mail: deposit@ccdc.cam.ac.uk or www: http://www.ccdc.cam.ac.uk).

\section{Acknowledgements}

The work was supported by the Australian Research Council (DP0985481, which includes an APD Fellowship to MM). PR thanks the ARC for his ARF fellowship (DP0986999) and iVEC and the National Computational Infrastructure for the provision of computer time. DS thanks Curtin University for a Research Fellowship and the ARC for her DECRA (DE120101456). The authors thank Prof R. G. Compton at Oxford University for the kind donation of the microelectrode used for the electrochemical experiments. PW and MW wish to thank Curtin University for their APA. The authors acknowledge the facilities, scientific and technical assistance of the Australian Microscopy \& Microanalysis Research Facility at the Center for Microscopy, Characterization \& Analysis, The University of Western Australia, a facility funded by the University, State and Commonwealth Governments.

\section{References}

(1) Kirgan, R. A.; Sullivan, B. P.; Rillema, D. P. Top. Curr. Chem. 2007, 281, 45.

(2) Zhao, Q.; Huang, C. H.; Li, F. Y. Chem. Soc. Rev. 2011, 40, 2508.

(3) Fernandez-Moreira, V.; Thorp-Greenwood, F. L.; Coogan, M. P. Chem. Commun. 2010, 46, 186.

(4) Lo, K. K. W. Top. Organomet. Chem. 2010, 29, 115.

(5) Bruckmeier, C.; Lehenmeier, M. W.; Reithmeier, R.; Rieger, B.; Herranz, J.; Kavakli, C. Dalton Trans. 2012, 41, 5026. 
(6) Guttentag, M.; Rodenberg, A.; Kopelent, R.; Probst, B.; Buchwalder, C.; Brandstatter, M.; Hamm, P.; Alberto, R. Eur. J. Inorg. Chem. 2012, 59.

(7) Ferrer, M.; Rodriguez, L.; Rossell, O.; Lima, J. C.; Gomez-Sal, P.; Martin, A. Organometallics 2004, 23, 5096.

(8) Grills, D. C.; Fujita, E. J. Phys. Chem. Lett. 2010, 1, 2709.

(9) Mauro, M.; Procopio, E. Q.; Sun, Y. H.; Chien, C. H.; Donghi, D.; Panigati, M.; Mercandelli, P.; Mussini, P.; D'Alfonso, G.; De Cola, L. Adv. Funct. Mater. 2009, 19, 2607.

(10) Wrighton, M.; Morse, D. L. J. Am. Chem. Soc. 1974, 96, 998.

(11) Worl, L. A.; Duesing, R.; Chen, P. Y.; Dellaciana, L.; Meyer, T. J. J. Chem. Soc. Dalton Trans.

$1991,849$.

(12) Vlcek, A.; Zalis, S. Coord. Chem. Rev. 2007, 251, 258.

(13) Mullice, L. A.; Pope, S. J. A. Dalton Trans. 2010, 39, 5908.

(14) Cattaneo, M.; Fagalde, F.; Borsarelli, C. D.; Katz, N. E. Inorg. Chem. 2009, 48, 3012.

(15) Caspar, J. V.; Meyer, T. J. J. Phys. Chem. 1983, 87, 952.

(16) Lin, R. G.; Guarr, T. F. Inorg. Chim. Acta 1990, 167, 149.

(17) Lin, R. G.; Fu, Y. G.; Brock, C. P.; Guarr, T. F. Inorg. Chem. 1992, 31, 4346.

(18) Baiano, J. A.; Carlson, D. L.; Wolosh, G. M.; Dejesus, D. E.; Knowles, C. F.; Szabo, E. G.; Murphy, W. R. Inorg. Chem. 1990, 29, 2327.

9527.

(19) Gomez, E.; Huertos, M. A.; Perez, J.; Riera, L.; Menendez-Velazquez, A. Inorg. Chem. 2010, 49,

(20) Cooke, M. W.; Hanan, G. S. Chem. Soc. Rev. 2007, 36, 1466.

(21) Manimaran, B.; Thanasekaran, P.; Rajendran, T.; Lin, R. J.; Chang, I. J.; Lee, G. H.; Peng, S. M.; Rajagopal, S.; Lu, K. L. Inorg. Chem. 2002, 41, 5323.

(22) Slone, R. V.; Benkstein, K. D.; Bélanger, S.; Hupp, J. T.; Guzei, I. A.; Rheingold, A. L. Coord. Chem. Rev. 1998, 171, 221.

(23) Sun, S. S.; Lees, A. J. Coord. Chem. Rev. 2002, 230, 171.

(24) Procopio, E. Q.; Mauro, M.; Panigati, M.; Donghi, D.; Mercandelli, P.; Sironi, A.; D'Alfonso, G.; De Cola, L. J. Am. Chem. Soc. 2010, 132, 14397.

(25) Tapolsky, G.; Duesing, R.; Meyer, T. J. J. Phys. Chem. 1989, 93, 3885.

(26) Panigati, M.; Donghi, D.; D'Alfonso, G.; Mercandelli, P.; Sironi, A.; D'Alfonso, L. Inorg. Chem. 2006, 45, 10909.

(27) Donghi, D.; D'Alfonso, G.; Mauro, M.; Panigati, M.; Mercandelli, P.; Sironi, A.; Mussini, P.; D'Alfonso, L. Inorg. Chem. 2008, 47, 4243.

(28) Tapolsky, G.; Duesing, R.; Meyer, T. J. Inorg. Chem. 1990, 29, 2285.

(29) Silvester, D. S.; Uprety, S.; Wright, P. J.; Massi, M.; Stagni, S.; Muzzioli, S. J. Phys. Chem. C 2012, $116,7327$.

(30) Werrett, M. V.; Chartrand, D.; Gale, J. D.; Hanan, G. S.; MacLellan, J. G.; Massi, M.; Muzzioli, S.; Raiteri, P.; Skelton, B. W.; Silberstein, M.; Stagni, S. Inorg. Chem. 2011, 50, 1229.

(31) Koguro, K.; Oga, T.; Mitsui, S.; Orita, R. Synthesis 1998, 910.

(32) Hevia, E.; Pérez, J.; Riera, V.; Miguel, D.; Kassel, S.; Rheingold, A. Inorg. Chem. 2002, 41, 4673.

(33) Downward, A. J.; Steel, J. P.; Steenwijk, J. Aust. J. Chem. 1995, 48, 1625.

(34) Dows, D. A.; Haim, A.; Wilmarth, W. K. J. Inorg. Nucl. Chem. 1961, 21, 33.

(35) Heins, A. M. Spectrochim. Acta 1977, 33, 315.

(36) Palazzi, A.; Stagni, S.; Bordoni, S.; Monari, M.; Selva, S. Organometallics 2002, 21, 3774.

(37) Stagni, S.; Palazzi, A.; Zacchini, S.; Ballarin, B.; Bruno, C.; Marcaccio, M.; Paolucci, F.; Monari, M.; Carano, M.; Bard, A. J. Inorg. Chem. 2006, 45, 695. 
(38) Bullock, J. P.; Carter, E.; Johnson, R.; Kennedy, A. T.; Key, S. E.; Kraft, B. J.; Saxon, D.; Underwood, P. Inorg. Chem. 2008, 47, 7880.

(39) Vlcek, A. Top. Organomet. Chem. 2010, 29, 73.

(40) Dattelbaum, D. M.; Omberg, K. M.; Schoonover, J. R.; Martin, R. L.; Meyer, T. J. Inorg. Chem. 2002, 41, 6071.

(41) Dattelbaum, D. M.; Martin, R. L.; Schoonover, J. R.; Meyer, T. J. J. Phys. Chem. A 2004, 108, 3518.

(42) Palazzi, A.; Stagni, S. J. Organomet. Chem. 2005, 690, 2052.

(43) Palazzi, A.; Stagni, S.; Selva, S.; Monari, M. J. Organomet. Chem. 2003, 672, 130.

(44) Butler, R. N.; Garvin, V. C. J. Chem. Soc. Perk. Trans. 1 1981, 390.

(45) Butler, R. N.; Garvin, V. C.; Lumbroso, H.; Liegeois, C. J. Chem. Soc. Perk. Trans. 2 1984, 721.

(46) Butler, R. N.; Mcevoy, T. M. J. Chem. Soc. Perk. Trans. 2 1978, 1087.

(47) Costuas, K.; Rigaut, S. Dalton Trans. 2011, 40, 5643.

(48) Bard, A. J.; Faulkner, L. R. Electrochemical Methods: Fundamentals and Applications; Second ed.; John Wiley \& Sons: New York, 2001.

(49) Barrosse-Antle, L. E.; Bond, A. M.; Compton, R. G.; O 'Mahony, A. M.; Rogers, E. I.; Silvester, D. S. Chem. Asian J. 2010, 5, 202.

(50) Hapiot, P.; Lagrost, C. Chem. Rev. 2008, 108, 2238.

(51) Villegas, J. M.; Stoyanov, S. R.; Huang, W.; Rillema, D. P. Dalton Trans. 2005, 1042.

(52) Striplin, D. R.; Crosby, G. A. Coord. Chem. Rev. 2001, 211, 163.

(53) Frisch, M. J.; Trucks, G. W.; Schlegel, H. B.; Scuseria, G. E.; Robb, M. A.; Cheeseman, J. R.; Scalmani, G.; Barone, V.; Mennucci, B.; Patersson, G. A.; Nakatsuji, H.; Caricato, M.; Li, X.; Hratchian, H. P.; Izmaylov, A. F.; Bloino, J.; Zheng, G.; Sonnengerg, J. L.; Hada, M.; Ehara, M.; Toyota, K.; Fukuda, R.; Hasegawa, J.; Ishida, M.; Nakajima, T.; Honda, Y.; Kitao, O.; Nakai, H.; Vreven, T.; Montgomery, J., J. A.; Peralta, J. E.; Ogliaro, F.; Bearpark, M.; Heyd, J. J.; Brothers, E.; Kudin, K. N.; Staroverov, V. N.; Kobayashi, R.; Normand, J.; Raghavachari, K.; Rendell, A.; Burant, J. C.; Iyengar, S. S.; Tomasi, J.; Cossi, M.; Rega, N.; Millam, J. M.; Klene, M.; Knox, J. E.; Cross, J. B.; Bakken, V.; Adamo, C.; Jaramillo, J.; Gomperts, R.; Stratmann, R. E.; Yazyev, O.; Austin, A. J.; Cammi, R.; Pomelli, C.; Ochterski, J. W.; Martin, R. L.; Morokuma, K.; Zakrzewski, V. G.; Voth, G. A.; Salvador, P.; Dannenberg, J. J.; Dapprich, S.; Daniels, A. D.; Farkas, O.; Foresman, J. B.; Ortiz, J. V.; Cioslowski, J.; Fox, D. J. Gaussian 09, Revision B.01 Wallingford CT, 2009.

(54) Tomasi, J.; Mennucci, B.; Cammi, R. Chem. Rev. 2005, 105, 2999.

(55) Scandola, F.; Argazzi, R.; Bignozzi, C. A.; Chirboli, C.; Indelli, M. T.; Rampi, M. A. Coord. Chem. Rev. 1993, 125, 283.

(56) Crosby, G. C.; Demas, J. N. J. Phys. Chem. 1971, 75, 991.

(57) Eaton, D. F. Pure Appl. Chem. 1988, 60, 1107.

(58) Silvester, D. S.; Wain, A. J.; Aldous, L.; Hardacre, C.; Compton, R. G. J. Electroanal. Chem. 2006, $596,131$.

(59) Gritzner, G.; Kuta, J. Pure Appl. Chem. 1984, 56, 461.

(60) Rogers, E. I.; Silvester, D. S.; Poole, D. L.; Aldous, L.; Hardacre, C.; Compton, R. G. J. Phys. Chem. C 2008, 112, 2729.

(61) Andrae, D.; Haussermann, U.; Dolg, M.; Stoll, H.; Preuss, H. Theor. Chim. Acta 1990, 77, 123.

(62) Sheldrick, G. M. Acta Cryst. 2008, A64, 112. 